Check for updates

Cite this: RSC Chem. Biol., 2021, 2, 612

Received 28th March 2020

Accepted 21st December 2020

DOI: 10.1039/d0cb00036a

rsc.li/rsc-chembio

\title{
Mechanism-based inhibitors of SIRT2: structure-activity relationship, X-ray structures, target engagement, regulation of $\alpha$-tubulin acetylation and inhibition of breast cancer cell migration $\dagger$
}

\author{
Alexander L. Nielsen, (D) ${ }^{a}$ Nima Rajabi, $\ddagger^{a}$ Norio Kudo, ${ }^{b}$ Kathrine Lund $\varnothing$, \\ Carlos Moreno-Yruela, (D) Michael Bæk, (D) ${ }^{a}$ Martin Fontenas, ${ }^{a}$ Alessia Lucidi, ${ }^{a}$ \\ Andreas S. Madsen, $\S^{a}$ Minoru Yoshida ${ }^{b}$ and Christian A. Olsen (D) *a
}

\begin{abstract}
Sirtuin 2 (SIRT2) is a protein deacylase enzyme that removes acetyl groups and longer chain acyl groups from post-translationally modified lysine residues. It affects diverse biological functions in the cell and has been considered a drug target in relation to both neurodegenerative diseases and cancer. Therefore, access to well-characterized and robust tool compounds is essential for the continued investigation of the complex functions of this enzyme. Here, we report a collection of chemical probes that are potent, selective, stable in serum, water-soluble, and inhibit SIRT2-mediated deacetylation and demyristoylation in cells. Compared to the current landscape of SIRT2 inhibitors, this is a unique ensemble of features built into a single compound. We expect the developed chemotypes to find broad application in the interrogation of SIRT2 functions in both healthy and diseased cells, and to provide a foundation for the development of future therapeutics.
\end{abstract}

\section{Introduction}

The sirtuins are $\mathrm{NAD}^{+}$-dependent lysine deacylase enzymes that are highly conserved across species, with seven isoforms (SIRT1-7) present in humans. These enzymes share a common $\mathrm{NAD}^{+}$-binding pocket and catalytic core, but have different cellular expression profiles, subcellular localization, and substrate specificities. ${ }^{1,2}$ Sirtuins were originally reported to

\footnotetext{
${ }^{a}$ Center for Biopharmaceuticals \& Department of Drug Design and Pharmacology, Faculty of Health and Medical Sciences, University of Copenhagen, Universitetsparken 2, DK-2100, Copenhagen, Denmark. E-mail: cao@sund.ku.dk

${ }^{b}$ RIKEN Center for Sustainable Resource Science (S13), Hirosawa 2-1, Wako, Saitama 351-0198, Japan

${ }^{c}$ Novo Nordisk Foundation Center for Basic Metabolic Research, Faculty of Health and Medical Sciences, University of Copenhagen, Blegdamsvej 3B, DK-2200, Copenhagen, Denmark

$\dagger$ Electronic supplementary information (ESI) available: Supplementary schemes and figures, additional methods, compound characterization data, copies of HPLC chromatograms, and copies of NMR spectra. Accession codes: X-ray diffraction data, coordinates, and structure factors for the X-ray crystal structures are deposited with the PDB (http://www.wwpdb.org) under the accession numbers 7BOS (SIRT2:13) and 7BOT (SIRT2:23). See DOI: 10.1039/d0cb00036a

\$ Present address: Red Glead Discovery, 223 63, Lund, Sweden.

$\S$ Present address: Novo Nordisk A/S, DK-2880, Bagsværd, Denmark.
}

be $\varepsilon$ - $N$-acetyllysine (Kac) hydrolases, but in recent years, it has become evident that a variety of $\varepsilon-N$-acyllysine posttranslational modifications (PTMs) can be removed by sirtuins,${ }^{3-8}$ as well as by zinc-dependent histone deacetylases (HDACs). ${ }^{9-14}$ These findings formed the basis of a paradigm shift in the understanding of lysine modifications and their influence on cell signaling and implication in disease. ${ }^{15}$ Sirtuin 2 is predominantly localized to the cytosol, where it is believed to act mainly as a deacetylase of microtubular proteins such as $\alpha$-tubulin, ${ }^{16,17}$ serving as a regulator in cell division and proliferation. ${ }^{18,19}$ Moreover, SIRT2 exhibits broad substrate scope, with a preference for long chain acyl groups $\left(\mathrm{C}_{6}-\mathrm{C}_{16}\right)$ in vitro ${ }^{5,20,21}$ and was also recently shown to target lysine benzoylation (Kbz). ${ }^{22}$ Generally, SIRT2 is recognized as a tumor suppressor, ${ }^{23}$ although knockdown and inhibition of SIRT2 also have a broad anticancer effect in human breast cancer cell lines by promoting c-Myc degradation. ${ }^{24}$ Additionally, SIRT2 has been linked to neurodegeneration, ${ }^{25,26}$ and it has been shown to promote lipolysis and prevent differentiation in mature adipocytes ${ }^{27}$ thus constituting a potential target for treatment of metabolic diseases and obesity. ${ }^{28,29}$ Interestingly, both activation and inhibition of SIRT2 appear to have therapeutic potential, depending on the biology under scrutiny. Accordingly, the complex role of SIRT2 calls for further 
a. Small molecules.
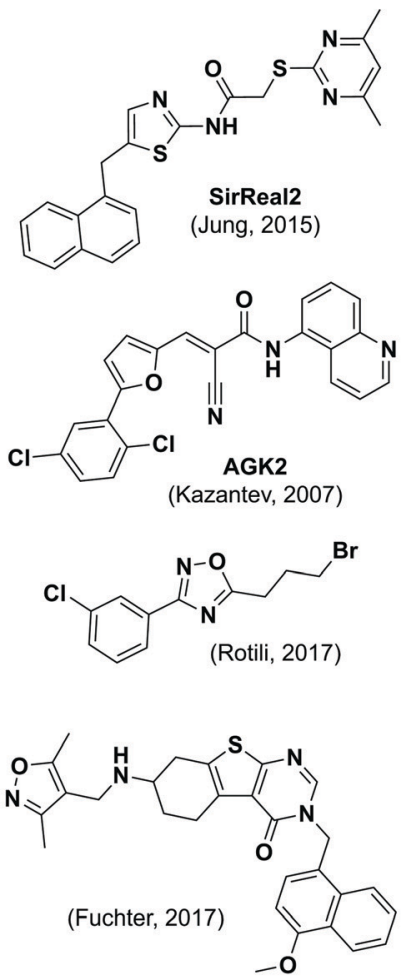

b. Chimeric compounds.

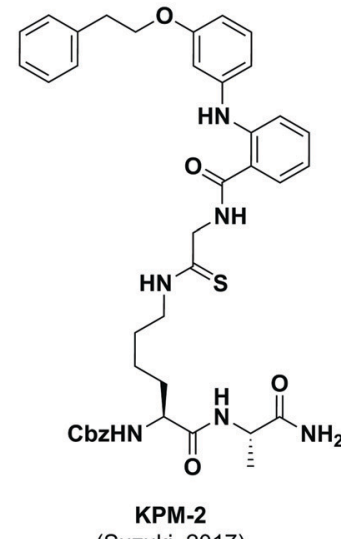

(Suzuki, 2017) c. Peptide macrocycles.

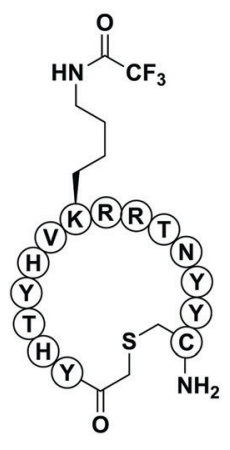

S2iL5

(Suga, 2014) d. Mechanism-based inhibitros.

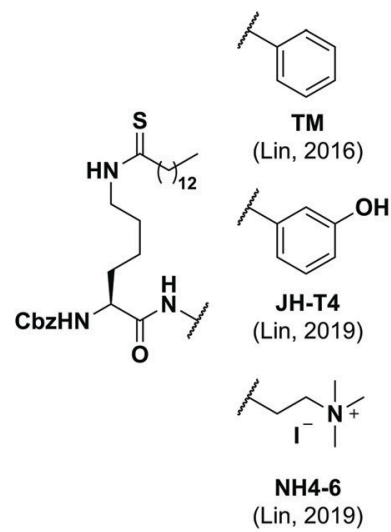

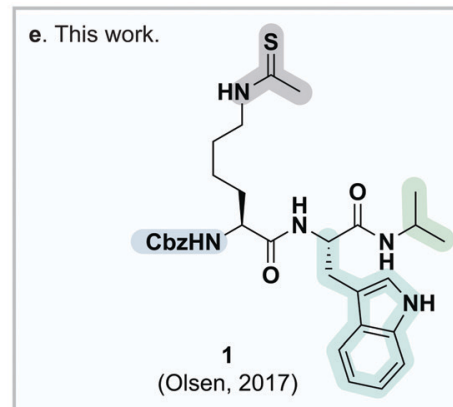

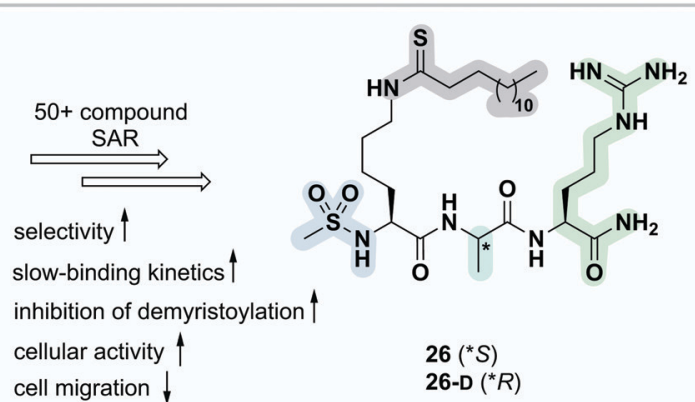

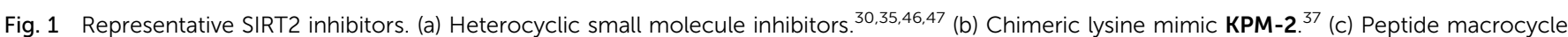
S2iL5. ${ }^{34}$ (d) Mechanism-based inhibitors based on modified lysine. ${ }^{24,32,40}$ (e) Summary of this study.

investigation and development of tool compounds to enable these endeavors.

Numerous SIRT2 inhibitors have been reported recently (Fig. 1), ${ }^{24,30-48}$ some of which are commercially available (e.g., SirReal2, AGK-2, tenovin-6). However, all of these compounds are endowed with limitations such as lack of isozyme selectivity, lack of potency (revealed by limited ability to inhibit demyristoylase activity), and/or poor solubility. We therefore embarked on a mechanism-based and substrate-mimicking approach to develop novel inhibitors of SIRT2 with improved attributes and efficacy.

Efforts of numerous groups over the last two decades have led to almost 30 X-ray crystal structures, including several co-crystal structures with ligands and inhibitors. ${ }^{34-40,49-56}$ This has provided insight into the binding mechanism and substrate scope of SIRT2 at the molecular level. In the present work, we have built on this knowledge to develop the most potent and selective SIRT2 inhibitors reported to date. These inhibitors were shown to potently inhibit demyristoylation in vitro, increase perinuclear acetylation levels of $\alpha$-tubulin in MCF-7 cells, and exhibit low nanomolar target engagement, as shown by cellular thermal shift assays. The inhibitors also exhibited inhibition of cell migration of MCF-7 breast cancer cells in culture. Finally, valuable insight into the stability of mechanism-based thioamide- and thiourea-containing sirtuin inhibitors in human serum was obtained, which will serve as useful guidance for future studies.

\section{Methods}

For general experimental information, chemical synthesis, compound characterization data, additional methods, and copies of analytical HPLC chromatograms and NMR spectra of novel compounds, please consult the ESI. $\dagger$

\section{Materials and methods for the biochemical assays}

SIRT1 (aa 193-741 with N-terminal GST-tag, $\geq 60 \%$ purity; cat. \#50012), SIRT2 (aa 50-356 with C-terminal His-tag, $\geq 90 \%$ purity; cat. \#50013), SIRT3 (aa 102-399 with N-terminal GST-tag; $\geq 64 \%$ purity; cat. \#50014), and SIRT6 (full length with N-terminal GST-tag, $\geq 75 \%$ purity; cat. \#50017) from BPS Biosciences (San Diego, CA). SIRT5 (aa 37-310 with N-terminal His-tag, $\geq 95 \%$ purity; cat. \#BML-SE555-0050) from Enzo Life Sciences (Farmingdale, NY). Purities were based on SDS-PAGE and Coomassie blue stain according to the supplier and all enzyme concentrations given were based on the stock concentrations determined by the supplier. Sirtuin substrates were obtained from previous studies: Ac-Gln-Pro-Lys-Lys(Ac)-AMC (QPKKac), ${ }^{20}$ Ac-Glu-Thr-Asp-Lys(Myr)-AMC (ETDKmyr), ${ }^{57}$ Ac-LysGln-Thr-Ala-Arg-Lys(Ac)-Ser-Thr-Gly-Gly-Trp-Trp-- $\mathrm{NH}_{2}$ (H3K9ac), ${ }^{20}$ and Ac-Leu-Gly-Lys(Suc)-AMC (LGKsuc). ${ }^{9}$ Assay buffer was prepared as described in Biomol International product sheets (BMLKI-143; Tris HCl (50 mM), NaCl (137 mM), KCl (2.7 mM), $\mathrm{MgCl}_{2}$ (1 mM), pH 8.0) with addition of BSA (1.0 mg mL ${ }^{-1}$, Sigma; cat. \#A2153) unless stated otherwise. Trypsin (10000 units $\mathrm{mg}^{-1}$, 
TPCK treated from bovine pancreas; cat. \#T1426) was purchased from Sigma (Steinheim, Germany). All other chemicals and solvents were of analytical grade and were used as obtained from commercial suppliers without further purification. All assays were performed in black low binding 96-well microtiter plates (Corning half-area wells; cat. \#3964), with duplicate series in each assay and each assay performed at least twice. All assays were performed in assay buffer, with appropriate concentrations of substrates and inhibitors obtained by dilution from $2-50 \mathrm{mM}$ stock solutions in either water or DMSO. The DMSO concentration in the final assay solution did not exceed $2 \%$ (v/v) unless stated otherwise. Control wells without enzyme and inhibitor (negative control) or without inhibitor (positive control) were included in each plate. Plates were analyzed using either a PerkinElmer Enspire or a BMG Labtech FLUOstar Omega plate reader with excitation at $360 \mathrm{~nm}$ and detecting emission at $460 \mathrm{~nm}$. Fluorescence measurements (RFU) were converted to [AMC] concentrations based on an [AMC]-fluorescence standard curve obtained in house, and all data analysis was performed using GraphPad Prism (version 8.1.2).

\section{End-point SIRT inhibition assays}

End-point inhibition assays were performed as previously described. ${ }^{58}$ In brief, the relevant substrate, $\mathrm{NAD}^{+}$(Sigma; cat. \#N5755), and inhibitor were added to each well and the experiment was initiated by addition of a freshly prepared solution of relevant sirtuin, for a final volume of $25 \mu \mathrm{L}$ per well. The following final concentrations were used: SIRT enzyme (100 nM; $600 \mathrm{nM}$ for SIRT6), substrate $(50 \mu \mathrm{M}), \mathrm{NAD}^{+}$ $(500 \mu \mathrm{M})$, and inhibitor $(1,10$ or $100 \mu \mathrm{M}$ or fold dilution series for dose-response assays). The plate was incubated at $37{ }^{\circ} \mathrm{C}$ for $60 \mathrm{~min}$, then a solution of trypsin and nicotinamide (NAM; $25 \mu \mathrm{L}, 5 \mathrm{mg} \mathrm{mL}^{-1}$ and $4 \mathrm{mM}$, respectively; final concentration $2.5 \mathrm{mg} \mathrm{mL}^{-1}$ and $2 \mathrm{mM}$, respectively) was added, and the assay development was allowed to proceed for $90 \mathrm{~min}$ at RT before fluorescence measurement and calculation of residual activity. For concentration-response assays, $\mathrm{IC}_{50}$ values were obtained by fitting the resulting data to the concentration-response equation using GraphPad Prism (version 8.1.2).

\section{Continuous enzyme inhibition assays}

Rate experiments for determination of kinetic parameters were evaluated under varying inhibitor concentrations. ${ }^{59}$ Buffer was prepared as previously described ${ }^{21}$ (HEPES/Na (50 mM), KCl (100 mM), Tween-20 (0.01\%), TCEP (0.2 mM), BSA (0.05 $\left.\mathrm{mg} \mathrm{mL}^{-1}\right)$, pH 7.4). SIRT2 was incubated with substrate, inhibitor, and trypsin in assay buffer, for a final volume of $50 \mu \mathrm{L}$ per well using the following final concentrations: SIRT2 (40 nM), ETDKmyr (10 $\mu \mathrm{M})$, inhibitor (100-0.20 $\mu \mathrm{M}$; 2-fold or 1.5-fold dilution series), $\mathrm{NAD}^{+}(200 \mu \mathrm{M})$, and trypsin $\left(20 \mathrm{ng} \mu \mathrm{L}^{-1}\right)$. In situ fluorophore release was monitored immediately by fluorescence readings recorded every 30 seconds for $60 \mathrm{~min}$ at $25{ }^{\circ} \mathrm{C}$. Assay progression curves of product concentration [P] $v s$. time $(t)$ were fitted to eqn (1) in order to calculate the apparent first-order rate constant for reaching equilibrium $\left(k_{\mathrm{obs}}\right)$ at each inhibitor concentration ( $v_{\mathrm{ss}}$ : steady-state velocity, $v_{\text {in }}$ : initial velocity), and kinetic parameters were extracted from either eqn (2) (mechanism A of slow binding, linear dependence of $k_{\mathrm{obs}}$ on the concentration of inhibitor) or eqn (3) (mechanism B of slow binding, hyperbolic dependence of $k_{\mathrm{obs}}$ on the concentration of inhibitor) as previously described. ${ }^{59,60}$ $\left(K_{\mathrm{M}}(\right.$ ETDKmyr $\left.)=1.8 \mu \mathrm{M}\right) .^{21}$

$$
\begin{gathered}
{[\mathrm{P}]=v_{\mathrm{ss}} t+\frac{v_{\text {in }}-v_{\mathrm{ss}}}{k_{\mathrm{obs}}}\left(1-\mathrm{e}^{-k_{\mathrm{obs}} t}\right)} \\
k_{\mathrm{obs}}=k_{1}\left(1+\frac{[\mathrm{S}]}{K_{\mathrm{M}}}\right)[\mathrm{I}]+k_{-1} \\
k_{\mathrm{obs}}=\frac{k_{2}}{[\mathrm{I}]+K_{i, 1}\left(1+\frac{[\mathrm{S}]}{K_{\mathrm{M}}}\right)}[\mathrm{I}]+k_{-2}
\end{gathered}
$$

\section{End-point pre-incubation assays}

SIRT2 and inhibitor were pre-incubated with or without $\mathrm{NAD}^{+}$ for $30 \mathrm{~min}$ at $37{ }^{\circ} \mathrm{C}$ in a total volume of $40 \mu \mathrm{L}$, prior to addition of substrate (and $\mathrm{NAD}^{+}$if excluded in pre-incubation), for a final volume of $45 \mu \mathrm{L}$. For pre-incubation excluding $\mathrm{NAD}^{+}$, the following concentrations were used: SIRT1/2 (113 nM during pre-incubation, giving $100 \mathrm{nM}$ after substrate and $\mathrm{NAD}^{+}$ addition), inhibitor (ranging from 113/100 $\mu \mathrm{M}$ down to 1.13/ $1.00 \mu \mathrm{M})$, substrate $(0 / 50 \mu \mathrm{M})$ and $\mathrm{NAD}^{+}(0 / 500 \mu \mathrm{M})$; For preincubation including $\mathrm{NAD}^{+}$, the following concentrations were used: SIRT2 (113 nM during pre-incubation, giving $100 \mathrm{nM}$ after substrate and $\mathrm{NAD}^{+}$addition), inhibitor (ranging from $113 / 100 \mu \mathrm{M}$ down to $1.13 / 1.00 \mu \mathrm{M})$, substrate $(0 / 50 \mu \mathrm{M})$ and $\mathrm{NAD}^{+}(563 / 500 \mu \mathrm{M})$. The plate was incubated at $37{ }^{\circ} \mathrm{C}$ for $30 \mathrm{~min}$, then a solution of trypsin and NAM $(45 \mu \mathrm{L}, 5.0 \mathrm{mg}$ $\mathrm{mL}^{-1}$ and $4 \mathrm{mM}$, respectively; final concentration $2.5 \mathrm{mg} \mathrm{mL}^{-1}$ and $2 \mathrm{mM}$, respectively) was added, and the assay development was allowed to proceed for $90 \mathrm{~min}$ at RT before fluorescence measurement and calculation of residual activity.

\section{HPLC-based SIRT inhibition assays}

All reactions were performed in black low-binding 96-well microtiter plates (Corning half-area wells; cat. \#3964), with each assay performed twice, using the same assay buffer as in end-point fluorescence-based assays (Tris, $\mathrm{pH}$ 8.0), but with the omission of BSA. Inhibition assays (concentration-response) were performed in a final volume of $40 \mu \mathrm{L}$. The following final concentrations were used: SIRT1 or SIRT2 $(20 \mathrm{nM})$, inhibitor (3-fold dilution series), H3K9ac $(50 \mu \mathrm{M})$ and $\mathrm{NAD}^{+}(500 \mu \mathrm{M})$. After incubating sirtuin, substrate, and inhibitor (when applicable) for 30 or $45 \mathrm{~min}$ at $37^{\circ} \mathrm{C}$, the reaction mixture was quenched by the addition of ice-cold $\mathrm{MeOH} / \mathrm{HCOOH}(94: 6(\mathrm{v} / \mathrm{v}), 20 \mu \mathrm{L})$. The samples were analyzed by HPLC on an Agilent 1260 Infinity II system equipped with a diode array detector. A gradient with eluent I (0.1\% TFA in water/MeCN 95:5 (v/v)) and eluent II $(0.1 \%$ TFA in MeCN (v/v)) rising linearly 0-40\% during $t$ 1.00$5.00 \mathrm{~min}$ was applied at a flow rate of $1.2 \mathrm{~mL} \mathrm{~min}^{-1}$. The obtained chromatograms at $280 \mathrm{~nm}$ were used to determine reaction progression, by determining area under the curve of the relevant peaks. 


\section{Chemical stability assays}

Serum stability. $400 \mu \mathrm{L}$ human male serum (Sigma; cat. \#H4522) was incubated at $37{ }^{\circ} \mathrm{C}$ for $15 \mathrm{~min}$. The serum was spiked with a DMSO-stock solution of the respective inhibitor to reach a final concentration of $150 \mu \mathrm{M}$. The mixture was shaken at $750 \mathrm{rpm}$ in an incubator at $37{ }^{\circ} \mathrm{C}$. Samples $(45 \mu \mathrm{L})$ were taken out at time points $(0 \mathrm{~min}, 15 \mathrm{~min}, 30 \mathrm{~min}, 1 \mathrm{~h}, 2 \mathrm{~h}$, $4 \mathrm{~h}, 6 \mathrm{~h}$, and $24 \mathrm{~h})$, quenched with aqueous urea $(6 \mathrm{M}, 50 \mu \mathrm{L})$, and incubated for $10 \mathrm{~min}$ at $4{ }^{\circ} \mathrm{C}$. Ice-cold acetonitrile $(100 \mu \mathrm{L})$ was added to each sample, which were incubated for another $10 \mathrm{~min}$ at $4{ }^{\circ} \mathrm{C}$. The samples were centrifuged for $90 \mathrm{~min}$ at $20000 \mathrm{~g}$ and filtered through $0.50 \mu \mathrm{m}$ filters before analysis by HPLC and subsequent integration of the peak areas of recovered compound over time. Half-lives $\left(t_{1 / 2}\right)$ were determined using GraphPad Prism (version 8.1.2) and fitted to a one-exponential decay equation, assuming first-order kinetics. Each assay was performed at least twice.

Cell-media stability. For compounds 25-D and 26-D, a similar procedure to the above described was performed using MEM cell-medium (Sigma; cat. \#2279) containing FBS (10\% (v/v)).

Buffer stability. A DMSO-stock solution of compound 20, 25-D, or 26-D was diluted to a final concentration of $100 \mu \mathrm{M}$ in assay buffer (Tris, pH 8.0). The mixture was shaken at $750 \mathrm{rpm}$ in an incubator at $37{ }^{\circ} \mathrm{C}$, and samples were taken out at several time points $(0,2,5$, and 10 days) and analyzed on by HPLC.

\section{Immunocytochemistry}

MCF-7 cells (150-1000 cells per well) were plated in Labtek Permanox Plastic Chamber slide system (Nunc, Thermo; cat. $\# 177445)$ and incubated overnight. After $24 \mathrm{~h}$, the cells were treated with inhibitor [TSA $(5 \mu \mathrm{M}), 26(5 \mu \mathrm{M}), \mathbf{T M}(25 \mu \mathrm{M})$ or 26-D $(25 \mu \mathrm{M})]$ or DMSO (control) for $6 \mathrm{~h}$, after which the cells were fixed in $4 \%$ formaldehyde for $15 \mathrm{~min}$ at RT. Cells were rinsed three times with PBS (pH 7.4) before blocking for $1 \mathrm{~h}$ with blocking buffer [ $5 \%$ goat-serum in PBS-T (PBS $+0.1 \%$ Triton$\mathrm{x} 100)]$ at RT and were then incubated with acetylated $\alpha$-tubulin antibody (1:300, Santa Cruz Biotechnology, Dallas, TX; cat. \#sc$23950 \mathrm{AC}$ ) in $5 \%$ goat-serum in PBS-T overnight at $4{ }^{\circ} \mathrm{C}$. The cells were washed in PBS three times and the fluorophore conjugated antibody diluted in blocking buffer (goat-anti mouse Alexa 488, Thermo, Waltham, MA; cat. \#A11011) was added 1:800 and incubated $1 \mathrm{~h}$ in the dark at RT. After three washes with PBS, the slides were mounted using ProLong ${ }^{\circledR}$ gold antifade mountant with DAPI (Thermo; cat. \#P36941) and cells were visualized using an inverted fluorescent microscope at $40 \times$. Images were generated using Visiopharm Technology (Visiopharm, Hørsholm, DK), processed using ImageJ (version 1.8) and Adobe Photoshop Lightroom (version 5.3).

\section{Cellular thermal shift assays ${ }^{61,62}$}

HEK293T cells were plated in $10 \mathrm{~cm}$ plates and incubated overnight. At $80-90 \%$ confluency, medium was replaced with culture medium containing SIRT2 inhibitor $(0.01 \mu \mathrm{M}$ for 26 , $0.10 \mu \mathrm{M}$ for $26-\mathrm{D}$ and $10 \mu \mathrm{M}$ for $\mathbf{T M}$ ) or respective volume of DMSO. The cells were treated for $1 \mathrm{~h}$ and the media removed by aspiration. The cells were collected in PBS by scraping, and pelleted by centrifugation $(300 g, 5 \mathrm{~min})$. Pellets were resuspended in PBS and spun down again. The washed cell pellets were suspended in PBS supplemented with complete EDTA-free protease inhibitor cocktail (COEDTAF-RO, Sigma, $800 \mu \mathrm{L}$ per cell treatment). The cell suspensions were aliquoted into PCR tubes $(60 \mu \mathrm{L})$ and heated to temperatures ranging from $37.0{ }^{\circ} \mathrm{C}$ to $75.0{ }^{\circ} \mathrm{C}$ for $3 \mathrm{~min}$. Then, samples were placed for $3 \mathrm{~min}$ at $25{ }^{\circ} \mathrm{C}$ in an Eppendorf Mastercycler Nexus thermal cycler. The cellular suspensions were then lysed by three consecutive freeze/thaw cycles, snap-freezing in a dry-ice/acetone bath followed by thawing at $25{ }^{\circ} \mathrm{C}$ in the thermal cycler and subsequent vortexing. The suspensions were subjected to centrifugation $(20000 \mathrm{~g}, 20 \mathrm{~min})$ at $4{ }^{\circ} \mathrm{C}$, and the supernatants were collected as whole-cell lysate. The isolated lysates were resolved by SDSPAGE in NuPAGE gels (4-12\% Bis-Tris, Thermo; cat. \#P0322BOX) with MES running buffer (Thermo; cat. \#NP000202), and protein bands were transferred onto PVDF membranes (Thermo; cat. \#IB24001) using an iBlot 2 gel transfer device. Membranes were blocked in 5\% skim milk in TBS-T (TBS $+0.1 \%$ tween-20) for $1 \mathrm{~h}$ at RT. Subsequently, the membranes were washed with TBS-T $(3 \times 5 \mathrm{~min})$ followed by incubation with primary antibody in $5 \%$ bovine serum albumin in TBS-T $(1: 1000)$ overnight at $4{ }^{\circ} \mathrm{C}$. After another three cycles of washing with TBS-T, the membranes were incubated with horseradish peroxidase (HRP) conjugated secondary antibody in $2 \%$ skim milk in TBS-T (1:10 000) for $1 \mathrm{~h}$ at RT. After washing with TBS-T $(3 \times 5 \mathrm{~min})$ and TBS $(1 \times 5 \mathrm{~min})$, membranes were visualized using enhanced chemiluminescent reagents (Pierce ECL Western Blotting Substrate, Thermo; cat. \#32106) on a syngene PXi4 image analysis system. Antibodies: mouse anti-SIRT1 (Santa Cruz Biotechnology; cat. \#sc-74504), rabbit anti-SIRT2 (Cell Signaling Technology (CST); cat. \#12650), rabbit anti-SIRT3 (CST; cat. \#5490), Goat anti-rabbit IgG (H + L) HRP-conjugated (Thermo; cat. \#31466), Goat anti-mouse polyHRP (Thermo; cat. \#32230).

\section{Scratch assays}

MCF-7 cells were plated in ibidi 2-well culture inserts (ibidi Gmbh, Gräfelfing, Germany; cat. \#80209) in 24-well plates at 300000 cells per well and incubated overnight. After overnight incubation, the inserts were removed and the cells were washed once in PBS and fresh medium was added. Cells were left to settle for $15 \mathrm{~min}$ before adding culture medium containing SIRT2 inhibitor [TM $(5 \mu \mathrm{M}), 26(0.05 \mu \mathrm{M}), 26-\mathrm{D}(0.5 \mu \mathrm{M})]$ or a DMSO control. Brightfield images were taken at time points 0 , $2,4,6,8$, and $24 \mathrm{~h}$, and the gap areas for each image were calculated using ImageJ (version 1.8) and used to determine the $\%$ closure of the gaps at each time point.

\section{Crystallization and X-ray co-crystal structures}

Crystallization was obtained using the catalytic domain of human SIRT2 lacking loop regions comprising residues 292303. Final construct: residues (52-291) + (304-356). The SIRT2 catalytic domain (16 mg mL $\mathrm{mL}^{-1}$ ) and compound 13 or 23 (final concentration $1 \mathrm{mM}$ ) were mixed, and crystallization screening was performed using commercial kits (Hampton Research, 
Aliso Viejo, CA). Crystals for X-ray crystallography were obtained using $0.1 \mathrm{M}$ HEPES, $\mathrm{pH} 7.0,30 \%$ (v/v) with Jeffamine ED-2001, pH 7.0 for compound 13 or with $0.15 \mathrm{M}$ potassium bromide, $30 \%$ (w/v) polyethylene glycol monomethyl ether 2000 for compound 23 at $20{ }^{\circ} \mathrm{C}$. Crystals were frozen with liquid nitrogen using PEG400 10\% (w/v) as cryoprotectant. X-Ray diffraction data were collected at $100 \mathrm{~K}$ in a nitrogen gas stream at the synchrotron beamlines, PF-BL 5A, 17A at Photon Factory and X06DA at the Swiss Light Source. Data were processed and scaled with the XDS program package. ${ }^{63}$ The crystal structures were determined by the molecular replacement method with MOLREP ${ }^{64,65}$ using the structure of SIRT2 in complex with H3K9-myr peptide (PDB 4Y6L). ${ }^{56}$ Refinement and model building were performed with REFMAC5 $5^{65,66}$ and Coot. ${ }^{67}$ Coordinates of inhibitors were calculated in AceDRG. ${ }^{68}$ The geometric quality of the model was assessed with MolProbity. ${ }^{69}$ Data collection and refinement statistics are listed in Table S1 (ESI $\dagger$ ). Figures containing structural elements were created using PyMOL Molecular Graphics System (version 1.8.0.6., Schrödinger, LLC).

\section{Results}

\section{Structure-activity relationship study and X-ray crystallography}

During our previous structure-activity relationship (SAR) study that targeted SIRT5, ${ }^{58}$ we found that thioacetamide 1 (Scheme 1a) did not inhibit SIRT5 but rather exhibited inhibition of SIRT2 $(14 \%$ at $10 \mu \mathrm{M})$ and could therefore serve as a starting point for the development of potent substrate-mimicking inhibitors of SIRT2. While thioacetamide-based compounds had already been reported to inhibit SIRT2, ${ }^{70,71}$ we turned our attention to longer-chain acyl groups, inspired by the $\varepsilon-N$ thiomyristoyllysine-based inhibitor, TM, developed by Lin and co-workers. ${ }^{24}$ Similar to our findings for SIRT5, the initial series of compounds (2-5, Scheme $\mathbf{1 b}$ ) revealed that thioamide- and thiourea-based $\varepsilon$ - $N$-acyllysine mimics (compounds 2 and 3 , respectively) led to highly potent inhibitors. Interestingly, introduction of analogous hydrazide or inverted amide moieties (compounds $\mathbf{4}$ and 5, respectively), which have previously been reported to serve as sirtuin inhibitors, ${ }^{72,73}$ exhibited only limited inhibition in our assays at $100 \mu \mathrm{M}$ concentration of the compounds. Because the thiourea modifications can be introduced in a late stage of the compound preparation, we chose the thiourea moiety for the subsequent compound series.

We then gained inspiration from the X-ray co-crystal structure of SIRT2 bound to the 14-mer macrocyclic inhibitor S2iL5, ${ }^{34}$ which is an analog of macrocyclic inhibitors discovered by Suga and co-workers using mRNA-display technology. ${ }^{42}$ This structure indicated electrostatic interactions between the guanidinium group of the arginine in the $i+2$ position ( $i$ : position of the modified lysine residue) and two nearby glutamic acid residues of SIRT2 (E116 and E120), prompting us to extend the scaffold by one additional C-terminal amino acid residue. This also enabled a solid-phase peptide synthesis (SPPS) approach, using the Rink amide linker ${ }^{74}$ to provide ready access to compounds 6-12 (Scheme 1c, for synthesis see Scheme S4, ESI $\dagger$ ). Gratifyingly, potency was improved up to 5 -fold by the $i+2$ extension. However, it proved challenging to determine meaningful $\mathrm{IC}_{50}$ values for compounds of this potency using our standard deacetylation assay, because stoichiometric inhibition was reached. We therefore determined compound potency in a similar demyristoylation assay using our previously developed myristoylated substrate (Ac-ETDKmyr-AMC), ${ }^{21,57}$ which has a substantially lower $K_{\mathrm{M}}$ value than acetylated substrates for SIRT2. ${ }^{21}$ The values for deacetylation (shown with an asterisk in Scheme 1), thus remain virtually constant throughout the attempts to improve upon compound affinity, while the ability to inhibit demyristoylation provides a more sensitive read-out of inhibitory potency.

The inhibition of the SIRT2 demyristoylase activity by compounds 6-12 revealed equipotency for positively and negatively charged amino acids and lower potency for the neutral residues (7 and 12). Thus, we selected compound 9, containing an arginine residue in the $i+2$ position, for further modification, due to a presumed positive effect on solubility and cell permeability. Reintroduction of a short-chain thioacetyl group (compounds S1-S4, Scheme S1, ESI $\dagger$ ) led to significantly decreased potency against SIRT2, while displaying respectable inhibition against SIRT1, further emphasizing the importance of a longer chain acyl group to target SIRT2 over SIRT1 and SIRT3. ${ }^{24,75}$

With compound 9 as the starting point, we then investigated the importance of the $i+1$ residue. In some X-ray co-crystal structures of SIRT2, residues surrounding this position are unresolved due to high flexibility and unstructured binding interactions. ${ }^{6,35}$ In particular, amino acids 289-304, which are located at the putative $i+1$ binding region, comprise a SIRT2specific insertion claimed to be stabilized by-and indeed resolved in the co-crystal structure with-the macrocycle S2iL5. ${ }^{34}$ We therefore investigated the importance of the $i+1$ residue by varying its charge, steric bulk, and stereochemistry in analogs 13-23 (Scheme 1d). In agreement with the expected flexibility of the binding region, we found that all modifications except proline led to potent compounds against the deacetylation activity of SIRT2. However, the inhibition data against demyristoylation activity revealed that the D-Ala (21) or 2-aminobutyric acid (Aib) (23) containing analogues were less potent, showing that stereochemistry at this position is more important for binding affinity than side chain functionality.

At this stage, we obtained diffraction-quality crystals of SIRT2 with compounds 13 and 23 bound and were able to solve X-ray co-crystal structures of both complexes at $1.7 \AA$ resolution (Fig. 2). Superimposing the two structures revealed highly similar conformations (Fig. $2 \mathrm{a}$ and b) as well as high similarity to a previously solved co-crystal structure of SIRT2 with a thiomyristoylated peptide substrate analog bound (Fig. 2c). More pronounced differences were observed when comparing our structures to a structure of the apo form of SIRT2 and the structure with S2iL5 bound (Fig. 2d). Not surprisingly, the upper zinc-binding domain and substrate binding pocket adopted a tighter conformation when bound to the macrocyclic peptide compared to our inhibitors, which require accommodation of the long fatty acyl side chain modification in the 

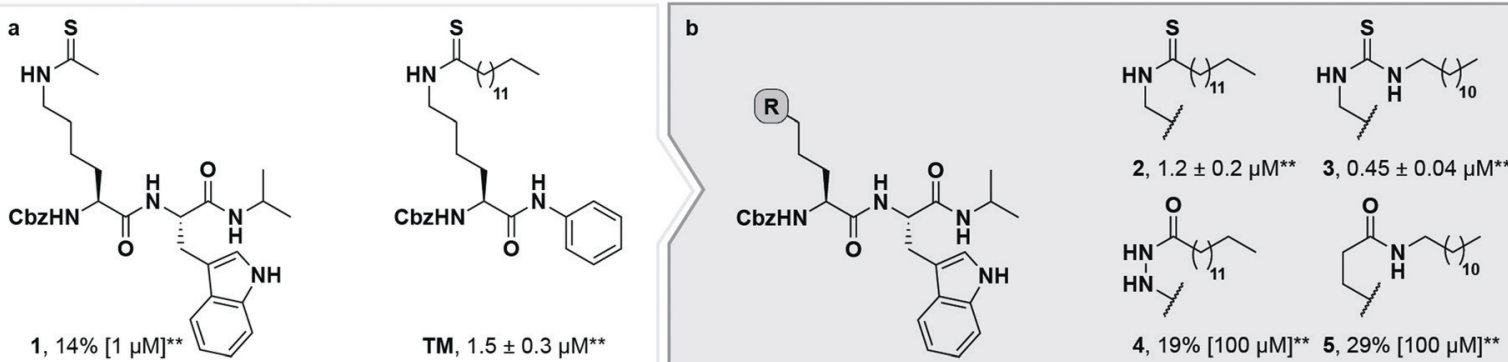

$\mathbf{4}, 19 \%[100 \mu \mathrm{M}]^{\star *} \mathbf{5}, 29 \%[100 \mu \mathrm{M}]^{\star *}$
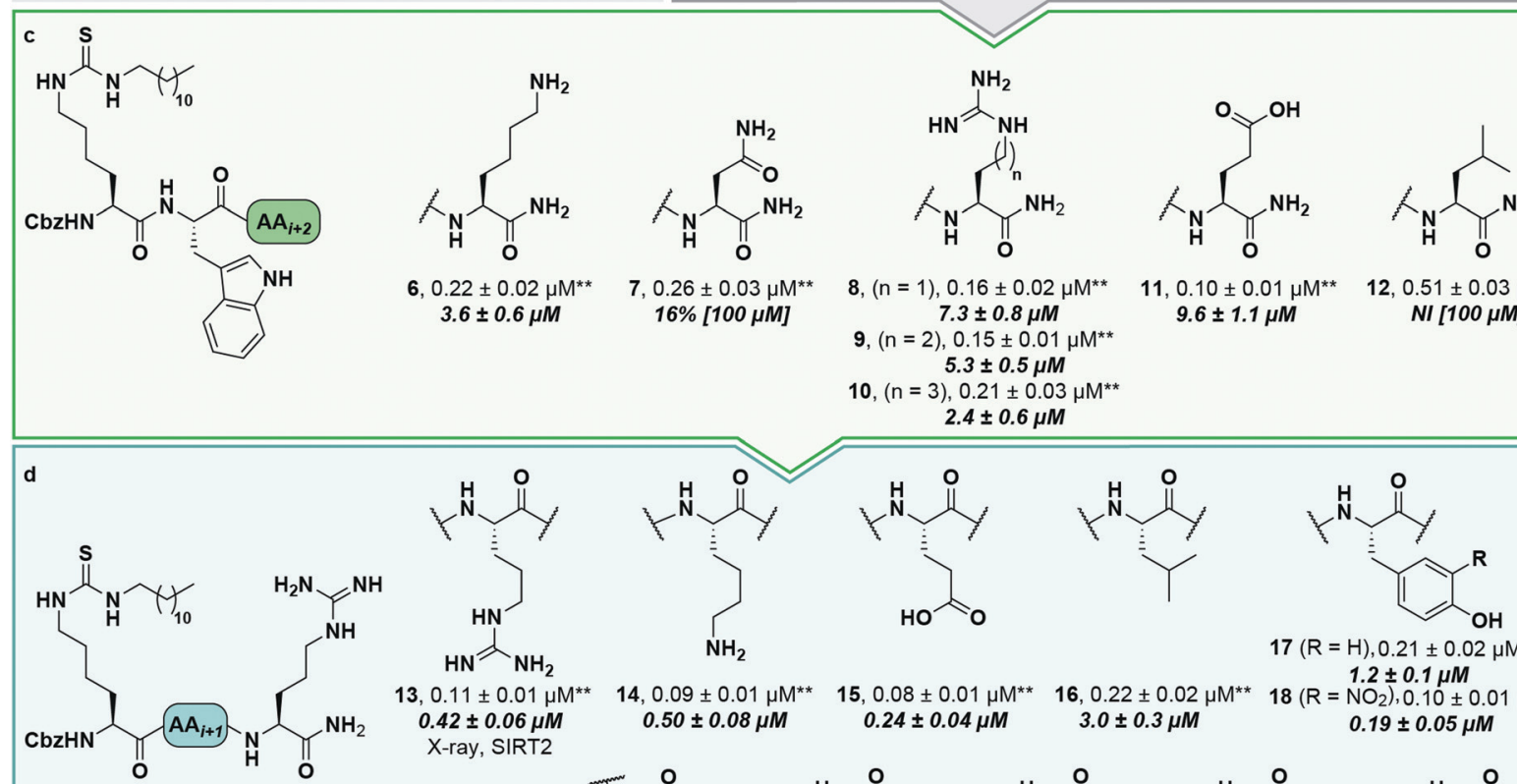

$17(\mathrm{R}=\mathrm{H}), 0.21 \pm 0.02 \mu \mathrm{M}^{*}$ $1.2 \pm 0.1 \mu M$<smiles>CCNC(CC(C)C)C(N)=O</smiles>

$12,0.51 \pm 0.03 \mu \mathrm{M}^{* *}$ NI $[100 \mu M]$

$\left(\mathrm{R}=\mathrm{NO}_{2}\right), 0.10 \pm 0.01 \mu \mathrm{M}^{*}$ $\begin{array}{lllll}0.42 \pm 0.06 \mu M & 0.50 \pm 0.08 \mu M & 0.24 \pm 0.04 \mu M & 3.0 \pm 0.3 \mu M & 0.19 \pm 0.05 \mu M\end{array}$
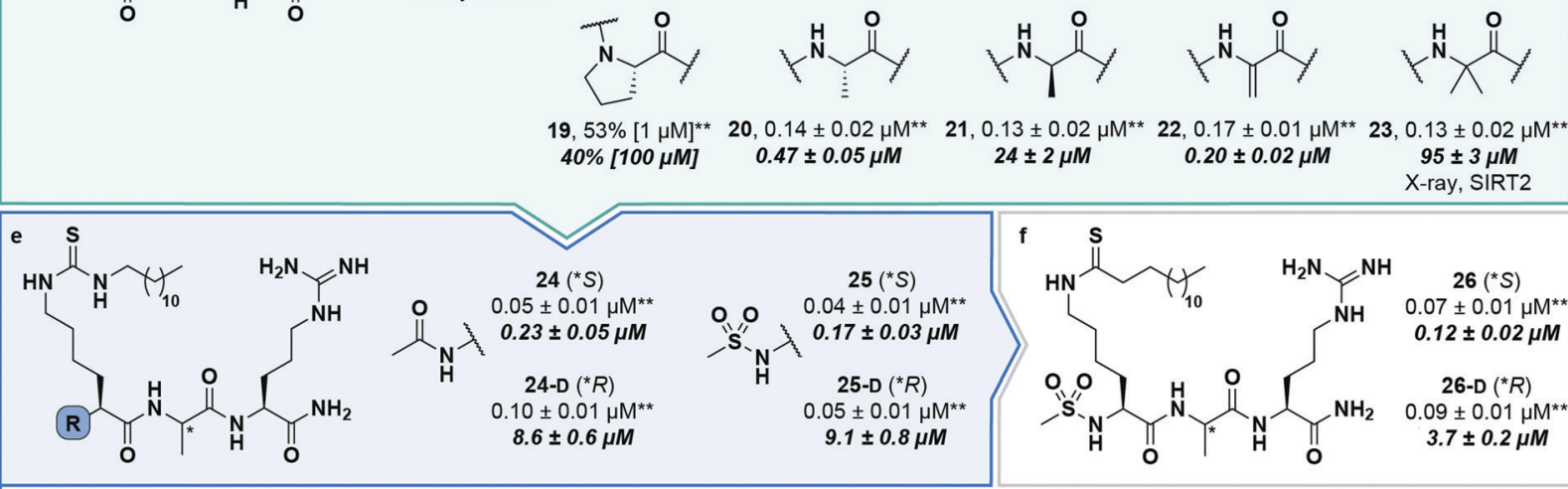

Scheme 1 Structure-activity relationship of SIRT2 inhibitors. Potencies for inhibition of the deacylase activity of recombinant SIRT2 (100 nM) against QPKKac (shown with asterisks**) or ETDKmyr (shown in bold/italics) as substrate $(50 \mu \mathrm{M})$ are given as mean $I_{50}$ values \pm standard deviation (SD) or \%inhibition. (a) Lead compounds. (b) Amide isosteres. (c) Optimization of position $i+2$. (d) Optimization of position +1 . (e) Optimization of $\mathrm{N}$-terminal group. (f) Final inhibitors. Data are based on two individual experiments performed in duplicate. See the ESI Table S2) for dose-response curves and selectivity profiling of additional inhibitors (S17-S23) against SIRT1-3. *A single asterisk denotes a stereogenic center.

substrate binding pocket (Fig. 2d), whereas the apo form adopted a more open structure. Generally, the most prominent inhibitor-enzyme interactions were through backbone-backbone hydrogen bonding (Fig. 2e), in agreement with those observed from an X-ray co-crystal structure with a thiomyristoylated peptide bound to SIRT2 (Fig. 2f). ${ }^{6}$ On the other hand, a recent structure of SIRT2 with a glucose-containing analog of TM showed a different binding mode (Fig. $2 \mathrm{f}$ ) ${ }^{40}$ which could help explain the lower potency of $\mathbf{T M}$ analogs compared to inhibitors with a higher peptide content, due to loss of backbone-backbone interactions.

Finally, our structures indicated that both L-configured and $\alpha$-bis-substituted amino acids could be accommodated at the $i+1$ position (Fig. 2e and g), which was not reflected by the biochemical assay data. The structures also indicated high flexibility regarding the choice of side chains at both $i+1$ and $i+2$ positions, as no direct interactions with the enzyme were observed, which is in agreement with the obtained 

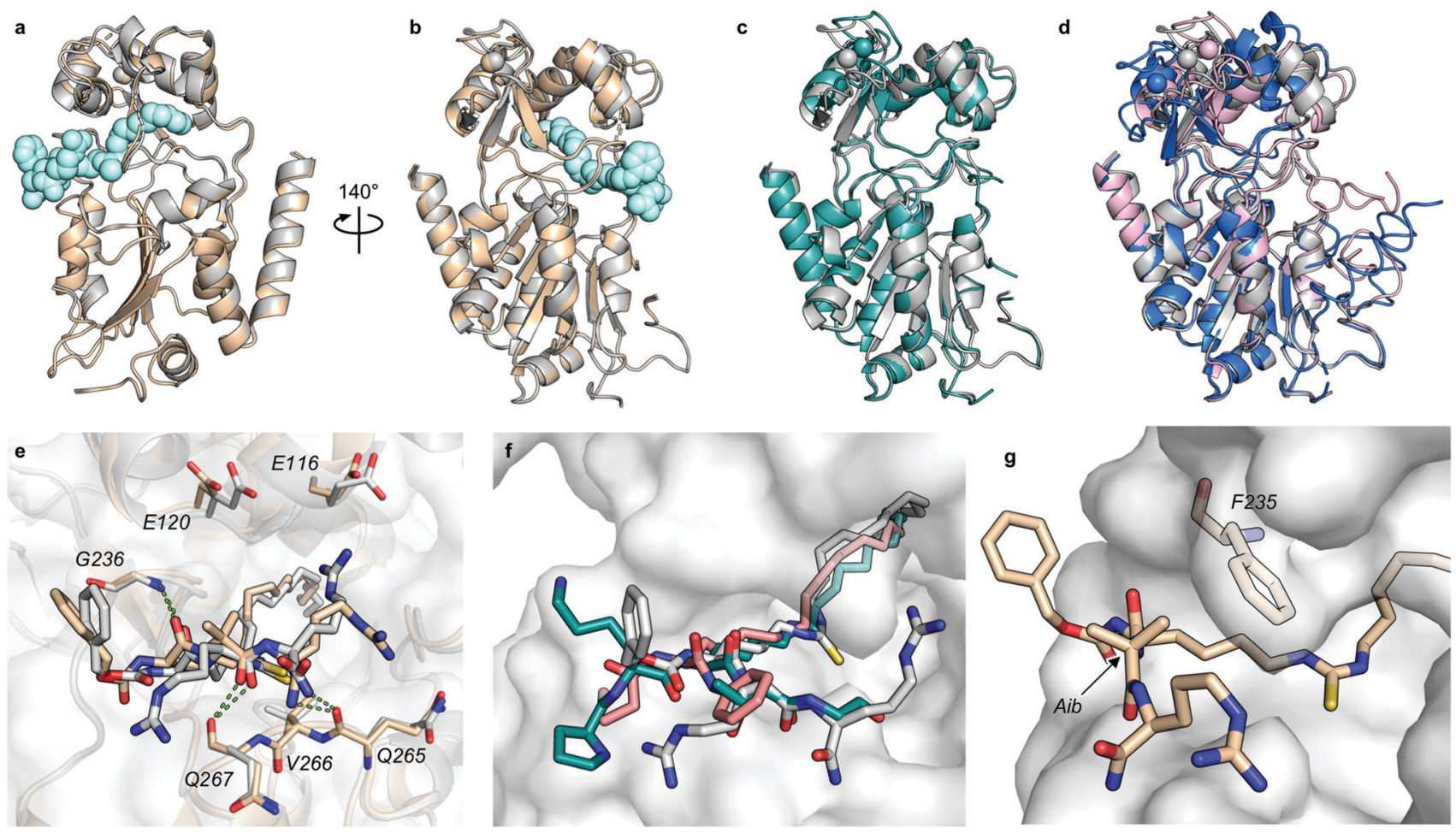

Fig. 2 X-Ray co-crystal structures of SIRT2 with compounds 13 and 23 bound. (a and b) Overall structure of SIRT2 co-crystallized with compounds 13 (gray) or 23 (tan). The ligand (13) is shown as light cyan spheres. (c) Overlay of the SIRT2:13 structure (gray) with previously solved co-crystal structure of SIRT2 with the thiomyristoylated peptide substrate analog BHJH-TM1 (PDB 4R8M; teal). (d) Overlay of the SIRT2:13 structure (gray) with previously solved structure of SIRT2 apo form (PDB 3ZGO; blue) and SIRT2 in complex with S2iL5 (PDB 4L3O; salmon). (e) Comparison of the exterior binding pocket of SIRT2 in complex with compound $\mathbf{1 3}$ (white) or $\mathbf{2 3}$ (tan). Dashed green lines highlight ligand-enzyme hydrogen bonding interactions. (f) Surface-view of SIRT2:13 (white) superimposed with BHJH-TM1 (teal) and "glucose-TM" (PDB 6NRO, pink). (g) Surface view of the exterior binding pocket of SIRT2:23.

compound potencies. Most prominently, there was a complete lack of electrostatic interactions between the guanidinium group at the $i+2$ position and E120 of SIRT2 (Fig. 2e-g), in contrast to what was observed for S2iL5. Again, this observation was in full agreement with the generally subtle differences observed in potency when substituting the $i+2$ position in our SAR. Finally, the structures indicated a significant degree of freedom regarding the choice of N-terminal substituents, as also found previously in our optimization of inhibitors of SIRT5. ${ }^{58}$ To address the importance of a select number of substituents at this position, we chose $\mathbf{2 1}$ (D-Ala) as the parent compound for the N-terminal SAR series, as the more potent compound 20 (L-Ala) already approached stoichiometric inhibition of demyristoylation. Thus, compounds S5-S10, 24-D, 25-D (Scheme 1 and Scheme S1, ESI $\dagger$ ) were evaluated for their ability to inhibit both deacetylation and demyristoylation, which revealed an improvement in potency for amides and sulfonamides compared to the carbamate (Cbz group), and flexibility in the degree of steric congestion as expected. To limit the hydrophobicity of our compounds, we therefore continued by synthesizing the L-Ala analogues of 24-D and 25-D to give $\mathbf{2 4}$ and 25 , respectively.

We then briefly revisited the importance of the $\varepsilon$ - $N$-acyllysine substitution. Truncating the acyl chain decreased the potency dramatically and in a more severe manner than observed for small molecule ligand $\mathbf{T M}$ and its shorter chain analogs ${ }^{24}$
(S11-S13; Scheme S1, ESI †). Additionally, introduction of oxygen atoms in the acyl chain to increase aqueous solubility greatly decreased the inhibitory activity (S14-S16, Scheme S1, ESI $\dagger$ ), again emphasizing the importance of a long hydrophobic PTM to maintain binding affinity. Finally, we reintroduced a thiomyristoyl group to furnish compounds 26 and 26-D that could serve as important tool compounds for comparing differences in biological effects between thioamides and thioureas. ${ }^{76}$ Both compounds were equipotent to their thiourea homologues.

\section{Compound selectivity and inhibition kinetics}

Despite the number of SIRT2 inhibitors previously reported, only few studies have addressed the inhibition of SIRT2 demyristoylase activity. ${ }^{21,77,78}$ Because $K_{\mathrm{m}}$ values for $\varepsilon$ - $N$-myristoyllysine-based substrates are in the order of 100 -fold lower than for corresponding acetylated substrates, ${ }^{6,21,79}$ only high-affinity inhibitors should be able to efficiently outcompete myristoylated substrates. Through our SAR study, we were able to inhibit SIRT2mediated demyristoylation and we even achieved inhibitor potencies to an extent where the inhibitor-enzyme ratio in the demyristoylation assays approached stoichiometry. We therefore performed continuous, trypsin-coupled progression curve assays $^{21}$ for selected compounds, which can report on the kinetics of inhibition. In addition, such assays may provide estimated $K_{i}$ values for inhibitors that do not exhibit the "standard" fast-on/fast-off steady-state kinetics, which prohibits 
approximation of $K_{i}$ values from end-point experiments, using the Cheng-Prusoff equation.

Compounds TM, S2iL5, 25, 26, and 26-D were chosen for this kinetic evaluation. TM did not show inhibition of SIRT2 in this assay, even upon addition of DMSO to help solubilize the inhibitor (10\% final concentration; Fig. 3a). Not surprisingly, due to the large peptide ring-size and presence of two Arg residues in the S2iL5 macrocycle, we found this compound incompatible with the trypsin present in the continuous assays (data not shown). Compounds 25 and 26, on the other hand, caused a substantial bending of the rate curves (Fig. $3 \mathrm{~b}$ and c), suggesting slow, tight-binding inhibition kinetics. ${ }^{80,81}$ This was also the case for compound 26-D; albeit, requiring substantially higher concentrations of the inhibitor (Fig. 3d), as would also be expected based on the end-point inhibition data (Scheme 1). For these three compounds, the apparent first-order rate constants to reach steady state $\left(k_{\text {obs }}\right)$ were calculated for each of the bending curves. Fitting the data from the two potent inhibitors (25 and 26) revealed hyperbolic relationships between $k_{\text {obs }}$ and inhibitor concentration, which indicates that the inhibition follows mechanism B of slow-binding, ${ }^{59}$ where the initially formed enzyme-inhibitor complex (EI) undergoes a slow conformational change to give a more stable complex EI* (Fig. 3e). The $K_{i}^{\text {app }}$ and residence time values could not be estimated for compounds $\mathbf{2 5}$ and 26, as the $k_{-2}$ rate constants approached zero in both experiments, revealing slow, tightbinding kinetics. On the other hand, the equilibrium constants for the first fast binding step $\left(K_{i, 1}\right)$ were in the same range as the measured $\mathrm{IC}_{50}$ values from end-point experiments, correlating with the relatively slow $k_{2}$ transition constants (Table S3, ESI $\dagger$ ). The less potent inhibitor 26-D followed mechanism A of slow-binding, where a single slow binding step is detected (Fig. 3e) and here the estimation of the $k_{-1}$ rate constant also approached zero, hampering the estimation of a $K_{i}^{\text {app }}$ value. The obtained on-rate $\left(k_{1}\right)$, however, was relatively low, which correlates with its limited inhibitory potency.

The potencies of our compounds were then benchmarked against a series of previously reported inhibitors applied as control compounds (Table 1). Compounds 25 and 26 showed superior potency against SIRT2 compared to SirReal2, TM, tenovin-6 and AGK-2. The macrocycle S2iL5 reached stoichiometric inhibition in the deacetylation assay but proved to be $>10$-fold less potent than compounds 25 and 26 when tested in the demyristoylation assay. In addition, no activity against demyristoylation could be recorded for any of the other control compounds at the highest concentration tested (Table 1). Because the most potent inhibitors reached stoichiometry in the SIRT2 deacetylation assay, determination of their selectivity indexes across SIRT1-3 was not possible. However, compounds 25 and 26 were substantially more selective towards SIRT2 over SIRT1 and SIRT3 than S2iL5, based on their higher potency against SIRT2 ( $>10$-fold), combined with their higher IC $_{50}$ values against SIRT3 and similar $\mathrm{IC}_{50}$ values against SIRT1 (Table 1). In addition, 25 and 26 did not inhibit SIRT5 or SIRT6 significantly (Table S4, ESI $\dagger$ ).

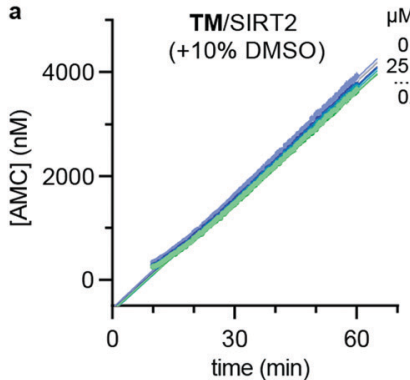

e

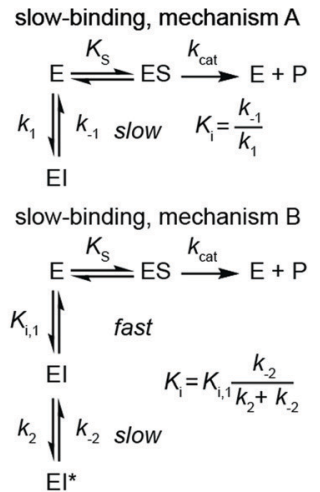

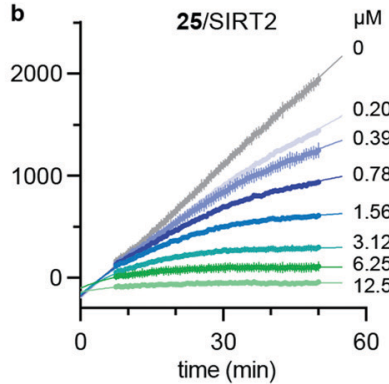

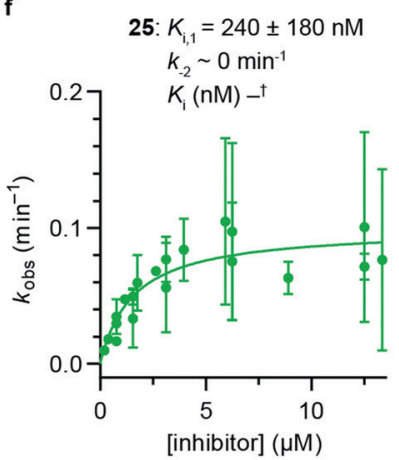

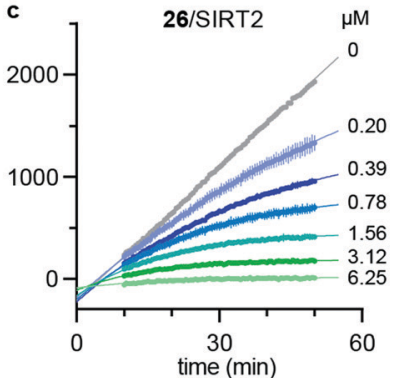

g

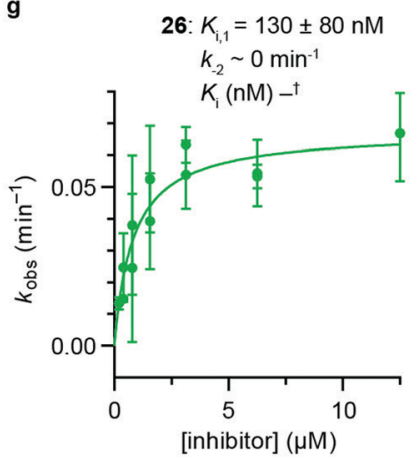

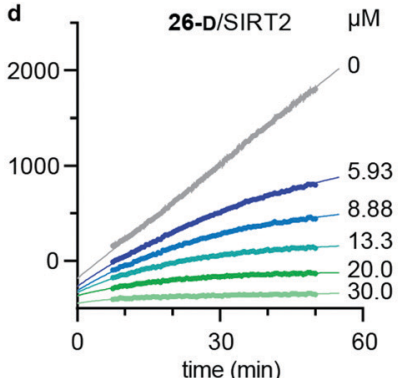

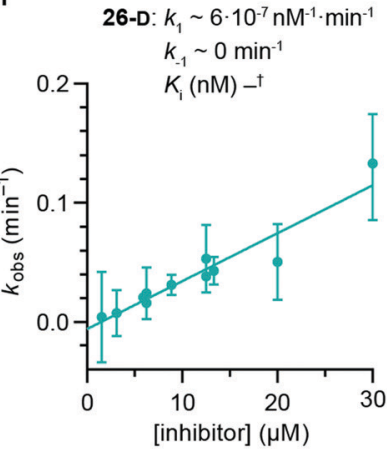

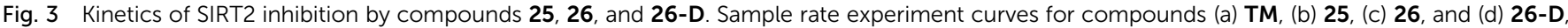

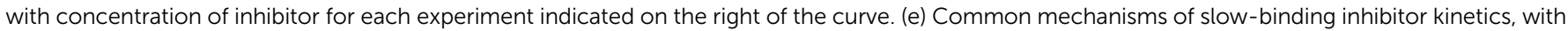

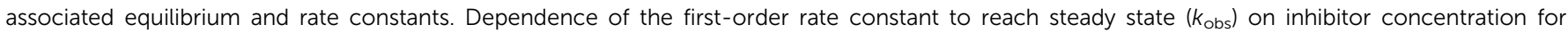

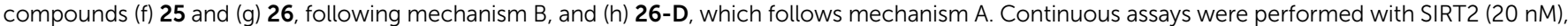

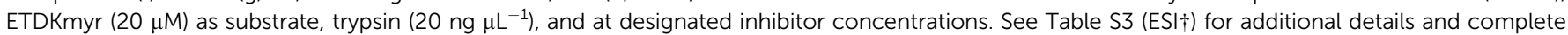
data fitting. 
Table $1 \quad I C_{50}$ values $(\mu M)$ or \%inhibition data for final compounds and control compounds ${ }^{a}$

\begin{tabular}{|c|c|c|c|c|}
\hline \multirow[b]{2}{*}{ Compound } & \multirow{2}{*}{$\frac{\text { SIRT1 }}{\text { QPKKac }}$} & \multicolumn{2}{|l|}{$\underline{\text { SIRT2 }}$} & \multirow{2}{*}{$\frac{\text { SIRT3 }}{\text { QPKKac }}$} \\
\hline & & QPKKac & ETDKmyr & \\
\hline SirReal2 & $37 \%[10 \mu \mathrm{M}]$ & $0.91 \pm 0.08$ & n.a. ${ }^{b}$ & n.a. \\
\hline TM & n.a. & $1.5 \pm 0.3$ & n.a. & n.a. \\
\hline Tenovin-6 & $<50 \%[100 \mu \mathrm{M}]$ & $19 \pm 1$ & n.a. & $<50 \%[100 \mu \mathrm{M}]$ \\
\hline AGK-2 & $62 \%[100 \mu \mathrm{M}]$ & $50 \pm 10$ & n.a. & $69 \%[100 \mu \mathrm{M}]$ \\
\hline S2iL5 & $0.24 \pm 0.03$ & Stoich. $^{c}$ & $2.1 \pm 0.2$ & $0.30 \pm 0.03$ \\
\hline 25 & $0.37 \pm 0.07$ & Stoich. ${ }^{c}$ & $0.17 \pm 0.03$ & $1.9 \pm 0.3$ \\
\hline 25-D & $3.6 \pm 0.7$ & Stoich. $^{c}$ & $9.1 \pm 0.8$ & $35 \pm 3$ \\
\hline 26 & $0.33 \pm 0.08$ & Stoich. $^{c}$ & $0.12 \pm 0.02$ & $2.0 \pm 0.4$ \\
\hline 26-D & $3.7 \pm 0.2$ & Stoich. ${ }^{c}$ & $3.3 \pm 0.3$ & $<50 \%[10 \mu \mathrm{M}]$ \\
\hline
\end{tabular}

${ }^{a}$ All values represent the mean of at least two individual assays performed in duplicate and are given in $\mu \mathrm{M} \pm \mathrm{SD}$. These assays were performed under standard conditions: substrate $(50 \mu \mathrm{M}), \mathrm{NAD}^{+}(500 \mu \mathrm{M})$, enzyme $(100 \mathrm{nM})$ without pre-incubation..$^{5 b}$ n.a. $=$ no activity, denotes no measurable inhibition at $10 \mu \mathrm{M}$ inhibitor concentration. ${ }^{c}$ Stoich. = inhibitior concentration is stoichiometric with enzyme concentration $(<100 \mathrm{nM})$.

Next, we investigated whether the observed inhibition of enzymatic deacylation could be recapitulated with a non-fluorogenic substrate. ${ }^{82}$ To address this, we chose a label-free HPLC-based assay, monitoring inhibition of histone 3 lysine 9 (H3K9) deacetylation, applying a dodecameric H3K9ac-containing peptide (Fig. 4a). We found the $\mathrm{IC}_{50}$ values of compounds $\mathbf{2 6}$, 26-D and S2iL5 to be in the nanomolar range, with 26 and 26-D being approximately 30 times more potent than S2iL5 and approaching stoichiometric inhibition in this assay as well (Fig. 4a and Table S5, ESI $\dagger$ ). Furthermore, TM showed more than three orders of magnitude lower potency than $26\left(\mathrm{IC}_{50} \sim\right.$ $40 \mu \mathrm{M}$ and $0.016 \pm 0.004 \mu \mathrm{M}$, respectively) when tested in this HPLC-based assay. This is not in accordance with a recent study by Lin, ${ }^{78}$ but corresponds well with another report where TM is used as a reference compound..$^{77}$ This may again be a result of the challenging handling of this compound, due to its limited aqueous solubility, which is in accordance with calculated $\log P$ and polar surface area (PSA) values, compared to the compounds developed here (Table S6, ESI $\dagger$ ). However, such discrepancies also highlight that $\mathrm{IC}_{50}$ values are highly dependent on the experimental conditions applied, which calls for determination in several different assay formats. ${ }^{83}$

Finally, we also performed assays with pre-incubation of selected inhibitors and SIRT2 with or without addition of $\mathrm{NAD}^{+}$, to address whether binding of $\mathrm{NAD}^{+}$to the enzyme is involved in the inhibition mechanism. For compounds TM, 3, 25-D and 26-D, substantially increased \%inhibition values were recorded upon pre-incubation including $\mathrm{NAD}^{+}$, which suggests a mechanismbased slow-binding mechanism involving the formation of stalled intermediate with adenosine diphosphate ribose (ADPR).$^{52}$ The only tested compound that did not exhibit this behavior was S2iL5 (Fig. 4b). ${ }^{58,84}$

\section{Compound stability}

Over the last decade, the considerable efforts in development of efficacious sirtuin modulators has furnished a number of potent inhibitors of commercial interest, of which some have entered clinical trials to document safety and efficacy in humans. ${ }^{85-90}$ However, there is a lack of studies addressing the chemical and metabolic stability of sirtuin inhibitors, except for one study of pronase susceptibility of linear $v s$. cyclic
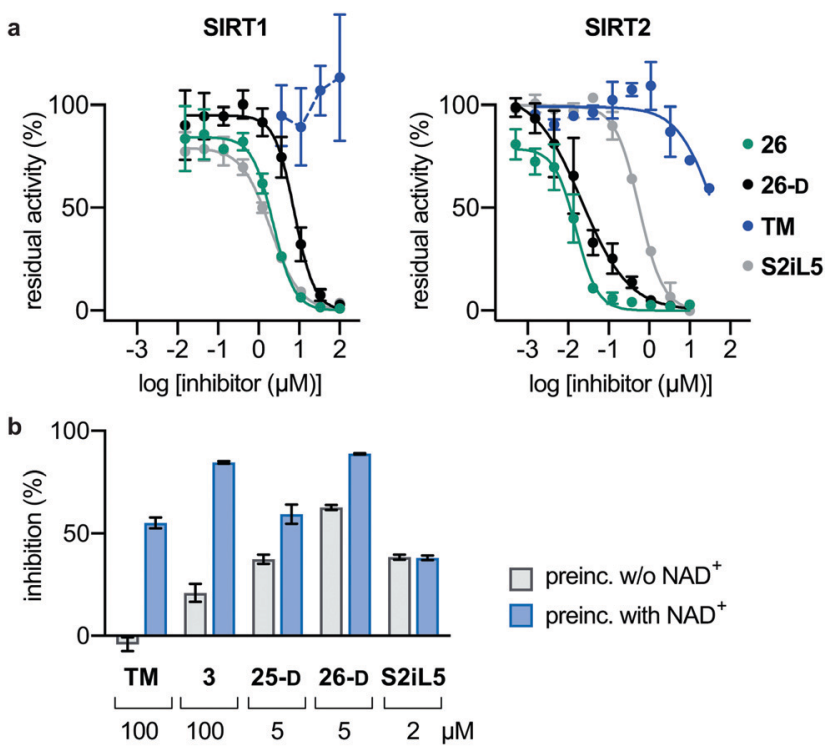

Fig. 4 Pre-incubation and HPLC-based sirtuin assays. (a) Inhibition of SIRT1 (20 nM) and SIRT2 (20 nM)-mediated deacetylation of the H3K9ac residue in a dodecameric peptide $(50 \mu \mathrm{M})$ determined by HPLC. Error bars represent mean \pm SEM of at least 2 independent experiments. See Table S4 (ESI $\dagger)$ for $\mathrm{IC}_{50}$ values against sirtuin mediated $\mathrm{H} 3 \mathrm{~K} 9 \mathrm{ac}$ deacetylation. (b) Pre-incubation (30 min), with or without $\mathrm{NAD}^{+}(500 \mu \mathrm{M})$ for selected compounds against SIRT2 (100 nM) demyristoylation using ETDKmyr $(50 \mu \mathrm{M})$ as substrate. Mean \pm SEM based on at least 2 independent experiments performed in duplicate.

sirtuin inhibitors. ${ }^{91}$ We recently addressed how stability differed greatly between short chain thioamide and thiourea compounds, ${ }^{76}$ which prompted us to investigate stability of selected inhibitors developed in this study. We first addressed the stability of 25-D (thiourea) and 26-D (thioamide) in assay buffer or growth cell medium supplemented with fetal bovine serum (FBS). Both compounds showed no sign of degradation in assay buffer for up to 10 days at $37{ }^{\circ} \mathrm{C}$ (Fig. S5, ESI $\dagger$ ) and were largely intact in growth medium for $24 \mathrm{~h}$ at $37^{\circ} \mathrm{C}$ (Fig. S6a, ESI $\dagger$ ). Next, we investigated the stability in human serum, which, in agreement with our previous observations, ${ }^{76}$ revealed that compound half-lives $\left(t_{1 / 2}\right)$ of thioamides (TM, 2, 26 and 26-D) were significantly higher than their thiourea counterparts $(3,25$ 


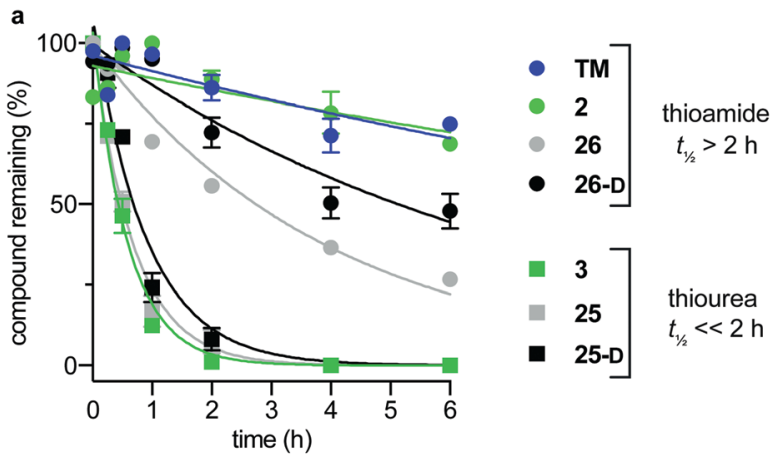

b $\begin{array}{ll}2 \text { (S-oxide) } & \text { compound } 2 \\ \mathrm{C}_{42} \mathrm{H}_{63} \mathrm{~N}_{5} \mathrm{O}_{5} \mathrm{~S} & \mathrm{C}_{42} \mathrm{H}_{63} \mathrm{~N}_{5} \mathrm{O}_{4} \mathrm{~S} \\ {[\mathrm{M}+\mathrm{H}]^{+} \cdot 750.4} & {[\mathrm{M}+\mathrm{H}]^{+} \cdot 734.4}\end{array}$
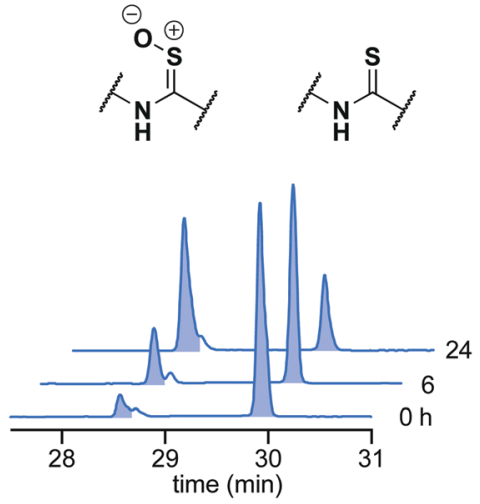

c
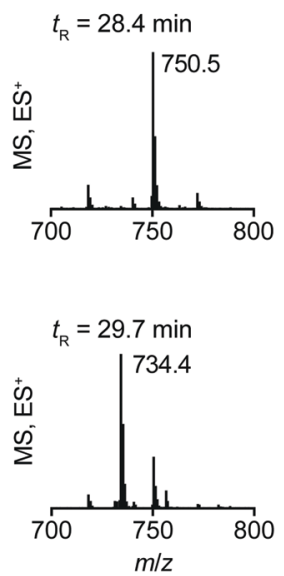

Fig. 5 Stability assays in human serum. (a) Stability assays of selected compounds in human male serum. (b) UV $\left(A_{280}\right)$ and (c) TIC (ES) chromatograms and mass spectra at relevant time points of compound $\mathbf{2}$ monitoring degradation in serum. Data are shown as mean values relative to the peak intensity at $t=0 \mathrm{~h} \pm \mathrm{SEM}, n=2-3$. For $t_{1 / 2}$ values, see Table S7 (ESI $\dagger$ ).

and 25-D), with the latter series being almost fully degraded in less than two hours (Fig. 5a). Additionally, we measured the stability of three known SIRT2 inhibitors for comparison. The compounds tenovin-6 and S2iL5 were rapidly degraded, whereas the small molecule inhibitor SirReal2 exhibited superior stability with no degradation even after $24 \mathrm{~h}$ (Fig. S6c, ESI $\dagger$ ).

The degradation of compounds 2 (thioamide) and 3 (thiourea) could be scrutinized in more detail by UPLC-MS analysis, because they contain tryptophan as a suitable chromophore. We found that the thioamide (2) was converted to a species with $[\mathrm{M}+16]^{+}$ $(\mathrm{m} / \mathrm{z})$ to a significant extent (Fig. $5 \mathrm{~b})$. Because thioamide S-oxides are known oxidative metabolites, we hypothesized that this is the major degradation product (Fig. 5b) ${ }^{92,93}$ The rapid degradation of the corresponding thiourea (3), on the other hand, led to large number of species that could not be structurally determined (Fig. S7, ESI $\dagger$ ). Release of hydrogen sulfide from both thioamide and thiourea motifs constitutes another possible mechanism of degradation..$^{94}$ These results suggest that enzymes other than peptidases (i.e. redox active enzymes) may play a significant role in compound turnover, which raises the question whether these compounds would stay intact in vivo. However, the low degree of degradation observed for the compounds in both assay buffer and cell growth medium with FBS render both thiourea and thioamide compounds amenable as probes for in vitro enzymatic assays and cell culture experiments.

\section{Target engagement of SIRT2 inhibitors in cells}

With our series of potent inhibitors in hand, we then assessed the cytotoxicity of a selection of $>15$ compounds, including control inhibitors TM and SirReal2, in cell culture experiments. We chose a panel of four cell lines, including immortalized human embryonic kidney cells (HEK293T), solid cervical cancer cells (HeLa), breast cancer cells (MCF-7), and T lymphocytes (Jurkat). Despite strong potency against SIRT2 in vitro, the compounds displayed lower degree of cytotoxicity than TM against all tested cell lines (Fig. S4 and Table S8, ESI†), begging the question whether the physicochemical properties of TM (Table S6, ESI $\dagger$ ) would render it more efficacious in cell-based assays. We therefore investigated the target engagement and selectivity across SIRT1-3, by performing cellular thermal shift assays in HEK293T cells, using western blots for the subsequent analysis (Fig. 6a and Fig. S9, ESI $\dagger$ ). ${ }^{61,62}$ Upon treatment with
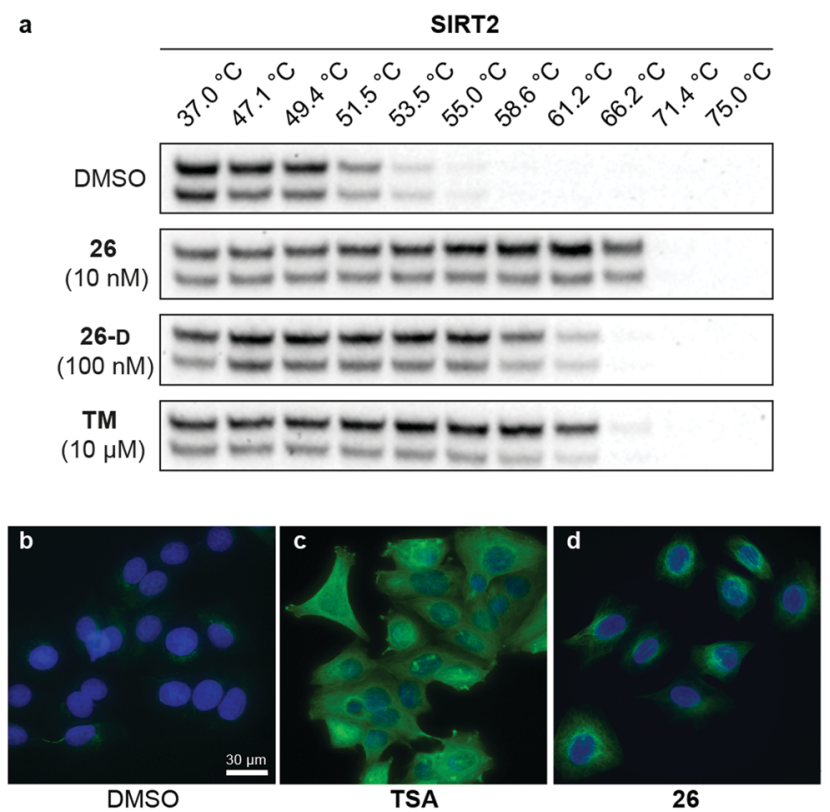

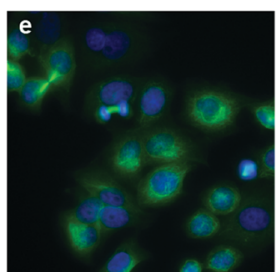

26-D

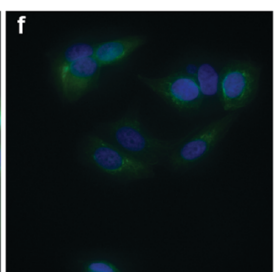

TM

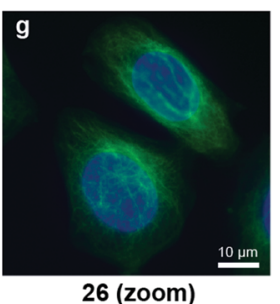

Fig. 6 Cellular target engagement and SIRT2i effect on perinuclear $\alpha$-tubulin acetylation. (a) Cellular thermal shift of SIRT2 in HEK293T cells subjected to $1 \mathrm{~h}$ treatment with inhibitor at designated concentrations or DMSO (vehicle). Please see Fig. S8 (ESI $\dagger$ ) for complete dataset against SIRT1-3 $(n=3)$. (b-g) Immunofluorescence images $(40 \times)$ of MCF-7 cells subjected to $6 \mathrm{~h}$ treatment with inhibitor [TSA $(5 \mu \mathrm{M}), 26(5 \mu \mathrm{M}), \mathrm{TM}(25 \mu \mathrm{M}), 26-\mathrm{D}(25 \mu \mathrm{M})]$ or DMSO (vehicle). (g) Zoomed image for compound 26. DAPI (blue, nuclear counterstain) and Ac- $\alpha$-tubulin (green). For additional images (single-filtered and zoomed) for all tested compounds, please see Fig. S9 (ESI $\dagger$ ). The data are representative images from two individual experiments. 
compound 26, 26-D or TM for 1 hour, a drastic increase in SIRT2 melting temperature was observed for all three compounds compared to the DMSO control. Particularly, compound 26 was found to give rise to $>15{ }^{\circ} \mathrm{C}$ thermal stabilization of SIRT2 at concentrations down to $10 \mathrm{nM}$ and no stabilization of SIRT1 and SIRT3 was observed under the same conditions (Fig. S9, ESI $\dagger$ ), verifying the selectivity of our compounds in cellulo. For TM, treatment with $10 \mu \mathrm{M}$ compound (1000-fold higher concentration) produced a slightly less pronounced thermal shift, rendering our optimized compound (26) substantially more efficient in this assay. All tested compounds 26, 26-D and TM exhibited excellent selectivity for SIRT2 over SIRT1 and SIRT3 (Fig. S9, ESI $\dagger$ ). Thus, these results suggest cellular thermal shift assays as an excellent complementary method to evaluate subtype selectivity across sirtuins along with in vitro profiling against recombinant enzymes.

\section{Modulation of $\alpha$-tubulin acetylation levels}

To investigate whether the compounds affected the protein acetylation level in cells, we then incubated HeLa and MCF-7 cells under a series of conditions and performed western blots on cell lysates to monitor changes in acetylation levels of $\alpha$-tubulin, which is a reported target of SIRT2 ${ }^{16}$ Unfortunately, we failed to observe any reproducible changes in acetylation levels upon treatment with inhibitor or TM as the positive control, $^{24}$ including experiments where SIRT2 was overexpressed or HDAC6 was inhibited by co-treatment with trichostatin A (TSA) ${ }^{47,95}$ (data not shown). Part of the explanation for these observations may be the differences in acetylation in asynchronous and mitotic cells. ${ }^{17}$ Instead, we applied immunofluorescence as a readout to detect changes in acetylated $\alpha$-tubulin levels in MCF-7 cells. Upon treatment with inhibitors ( 5 or $25 \mu \mathrm{M}$ for 6 hours), we were pleased to observe an increase in cellular fluorescence levels, particularly around the perinuclear microtubules, ${ }^{35}$ which is reported to be the main target of SIRT2 inhibition in cells. ${ }^{96}$ Treatment with the potent HDAC6 inhibitor TSA, on the other hand, resulted in hyperacetylation of $\alpha$-tubulin throughout the entire cell (Fig. 6c). Thus, the SIRT2-mediated effect on $\alpha$-tubulin acetylation is mainly perinuclear, compared to the global effects mediated by HDAC6 deacetylation, ${ }^{96}$ which may help explain why western blotting for total $\alpha$-tubulin acetylation was not an ideal measure of the effect of SIRT2 inhibition in our hands. This is in agreement with previous findings. ${ }^{35}$ However, inhibition of SIRT2 in primary $\mathrm{T}$ cells was recently shown to cause large increase in acetylated $\alpha$-tubulin levels as determined by western blotting, suggesting that cellular effects are highly cell type dependent. ${ }^{97}$

\section{Inhibition of breast cancer cell migration}

Due to the effects of our compounds on the acylation of the cytoskeleton and the validated target engagement, we next investigated the role of SIRT2 inhibition on breast cancer cell motility. In previous reports, SIRT2 has been implicated in the migration and invasion of gastric, colon, lung, and liver cancers. ${ }^{98-101}$ Therefore we investigated the effect of our lead
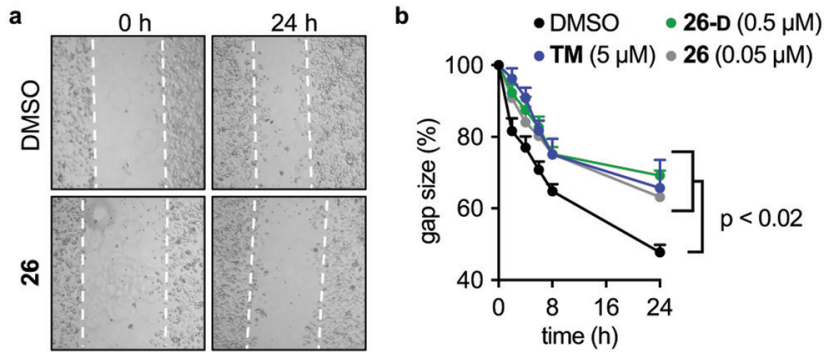

Fig. 7 SIRT2 inhibition elicits decreased breast cancer cell motility. (a) Representative images from a scratch assay in MCF-7 cells at time points 0 and $24 \mathrm{~h}(2.5 \times$ magnification). (b) Quantification of the gap size at different time points treated with inhibitors (TM, 26, and 26-D) at denoted concentrations relative to control ( $1 \% \mathrm{DMSO})$ treated cells \pm SEM. Data are shown as mean values relative to control ( $1 \%$ DMSO) treated cells \pm SEM, $n=4$. Statistical differences from control treated cells were determined by ordinary (multiple comparison) one-way ANOVA. Statistical $p$-values compared to DMSO control: $\mathrm{TM}=0.0042 ; 26<0.0001 ; 26-\mathrm{D}=0.0134$.

compounds on cell motility in MCF-7 cells. The effects of 26, 26-D, and TM inhibitors were investigated in a scratch assay (wound-healing assay) and all inhibitors decreased the degree of migration compared to the vehicle-treated control (Fig. 7a and b). Interestingly, knockdown of SIRT2 was recently shown to have the opposite effect on migration of A549 cells overexpressing RalB in culture, ${ }^{101}$ indicating that pharmacological modulation of the SIRT2 activity may provide a different outcome from enzyme knockdown/overexpression or that the effects are cell type specific. Additional experiments, including comparison with SIRT2 mediated knockdown, are required to investigate this in detail.

\section{Discussion}

Here, we report an elaborate SAR study, including X-ray co-crystal structures with intermediary compounds bound to SIRT2 to provide structural rationalization of the binding interactions. This furnished the most potent inhibitors of the SIRT2 histone deacetylase enzyme reported to date, which at the same time exhibit improved selectivity for the target compared to structurally similar isoforms, SIRT1 and SIRT3. The compounds were able to inhibit the demyristoylase activity of SIRT2 with unprecedented potencies, which is challenging due to the low $K_{\mathrm{m}}$ values of Kmyr-containing substrates. This further enabled us to glean insight into the binding kinetics of SIRT2 inhibition by applying continuous assay formats, which has not been achieved with SIRT2 deacetylation assays. ${ }^{102}$ Standard end-point dose-response assays do not take into account the kinetic behavior of inhibitors, ${ }^{80,81}$ which may give rise to $\mathrm{IC}_{50}$ values that vary substantially with specific assay conditions, especially if the inhibitor does not exhibit standard fast-on/fast-off kinetics. ${ }^{103}$ It is well documented that mechanismbased thioamide- and thiourea-containing inhibitors may form stalled intermediates with ADPR in the enzyme active sites, which can affect binding kinetics. ${ }^{58,104,105}$ Indeed, evaluation of compounds 25, 26, and 26-D in the continuous assays 
revealed slow, tight-binding kinetics with two different binding mechanisms. To our satisfaction, the estimated rate constants for the formation of inhibitor-enzyme complexes correlated well with the data obtained in our two other assay formats. We thus provide data from three different assay formats that are all are in agreement.

Furthermore, we provide measures of stability in buffer, cell culture medium, and human serum, which taken together will inform the development of future generations of mechanism-based inhibitors of sirtuins. Thiourea-containing compounds are more readily synthesized than thioamide counterparts, but they proved significantly less stable in human serum, highlighting probe $\mathbf{2 6}$ as the preferred choice for biological applications. Due to the similar potencies of inhibitors containing these two functional groups, however, we find the thiourea-based compounds useful during SAR studies, focusing on the optimization of compound potency and selectivity in vitro. At a later stage, the resulting lead compounds can then be prepared as their thioamide counterparts for biological studies as demonstrated in this work.

Compound 26, and also 26-D, exhibited cellular activity by causing increased levels of perinuclear acetylated $\alpha$-tubulin in MCF-7 cells in culture, as demonstrated by immunofluorescence experiments. Western blot analyses failed to demonstrate a reproducible effect on overall $\alpha$-tubulin acetylation in a range of experiments and conditions in our hands, including SIRT2 overexpression and/or treatment with additional HDAC inhibitors. Further evidence for target engagement with SIRT2 in cultured cells was achieved by performing cellular thermal shift assays in HEK293T cells, which showed substantial protein stabilization at just $10 \mathrm{nM}$ inhibitor concentration for compound 26. Finally, we show that migration of cultured MCF-7 cells is reduced by our SIRT2 inhibitors, which could have implications for inhibiting cancer metastasis.

Thus, the probes reported herein provide an attractive alternative to previously developed SIRT2 inhibitors by exhibiting potent inhibition of SIRT2 and a high degree of selectivity over SIRT1, 3, 5, and 6. Furthermore, the compounds exhibit target engagement and activity in cells, stability in serum, and aqueous solubility that should allow for intravenous dosing of animals without elaborate drug formulation. This combination of features is unique among SIRT2 inhibitors and we expect that the developed probes will therefore be valuable in the continued investigation of the function of SIRT2 as well as the development of novel therapeutics that target this enzyme.

\section{Author contributions}

A. L. N., N. R. and C. A. O conceptualized the study; A. L. N., N. R., M. F. and A. L. performed the chemical synthesis; A. L. N. and N. R. performed the biochemical characterization; C. M. Y. performed the enzyme kinetics; A. L. N., K. L. and M. B. performed the cell-based assays; A. L. N. performed the formal analysis of raw data; N. K. obtained the crystals and solved the structures; A. L. N. and C. A. O. wrote the original draft of the manuscript, and all authors reviewed and edited the final manuscript; C. A. O. acquired funding; A. S. M., M. Y., and C. A. O. supervised the study.

\section{Abbreviations}

\begin{tabular}{|c|c|}
\hline $\mathrm{ADPR}$ & Adenosine diphosphate ribose \\
\hline Aib & 2-Aminoisobutyric acid \\
\hline AMC & 7-Amino-4-methylcoumarin \\
\hline BSA & Bovine serum albumin \\
\hline $\mathrm{Cbz}$ & Benzyloxycarbonyl \\
\hline DAPI & $4^{\prime}, 6^{\prime}$-Diamidino-2-phenylindole \\
\hline DMSO & Dimethylsulfoxid \\
\hline ES & Electrospray \\
\hline FBS & Fetal bovine serum \\
\hline HDAC & Histone deacetylase \\
\hline HEK293T & Human embryonic kidney 293 cells \\
\hline HeLa & Henrietta Lacks (human cervical cancer cells) \\
\hline HEPES & $\begin{array}{l}\text { (4-(2-Hydroxyethyl)-1-piperazineethanesulfonic } \\
\text { acid) }\end{array}$ \\
\hline HRP & Horseradish peroxidase \\
\hline GFP & Green fluorescent protein \\
\hline $\mathrm{GI}_{50}$ & Half growth inhibitory concentration \\
\hline HPLC & High-performance liquid chromatography \\
\hline $\mathrm{IC}_{50}$ & Half maximal inhibitory concentration \\
\hline LC & Liquid chromatography \\
\hline MCF-7 & Michigan cancer foundation \\
\hline MEM & Minimum essential medium eagle \\
\hline NAD & Nicotinamide adenine dinucleotide \\
\hline NAM & Nicotinamide \\
\hline NMR & Nuclear magnetic resonance \\
\hline PBS & Phosphate-buffered saline \\
\hline PDB & Protein data bank \\
\hline PSA & Polar surface area \\
\hline PTM & Post-translational modification \\
\hline RT & Room temperature \\
\hline SAR & Structure-activity relationship \\
\hline SD & Standard deviation \\
\hline SEM & Standard error of the mean \\
\hline SIRT & Sirtuin \\
\hline SPPS & Solid-phase peptide synthesis \\
\hline TIC & Total ion chromatogram \\
\hline TSA & Trichostatin A \\
\hline HPLC & High performance liquid chromatography \\
\hline
\end{tabular}

\section{Conflicts of interest}

The authors declare no competing financial interest.

\section{Acknowledgements}

We thank Dr Iacopo Galleano, and Dr Martin Roatsch for donation of building blocks, as well as Julie E. Bolding, Kathrin S. Troelsen and Katrine Krydsfeldt for assistance with cell culture experiments. We thank Professor Thue W. Schwartz 
for access to equipment for performing immunofluorescence and wound-healing experiments. The X-ray crystallography was performed under the approval of the Photon Factory Program Advisory Committee (Proposal No. 2017G662 and 2019G669 and PSI Proposal No. 20181219 and 20181299). This work was supported by JSPS KAKENHI (JP19H05640; M. Y.), the Lundbeck Foundation (running cost grant R289-2018-2074; C. A. O.), the Carlsberg Foundation (2013-01-0333, CF15-011, and CF180442; C. A. O.), the Novo Nordisk Foundation (NF17OC0029464; C. A. O.), and the European Research Council (ERC-CoG725172-SIRFUNCT; C. A. O.). We thank the COST-Action CM1406 (EPICHEMBIO) for support.

\section{Notes and references}

1 P. Bheda, H. Jing, C. Wolberger and H. Lin, Annu. Rev. Biochem., 2016, 85, 405-429.

2 N. Rajabi, I. Galleano, A. S. Madsen and C. A. Olsen, Prog. Mol. Biol. Transl. Sci., Academic Press, 2018, vol. 154, pp. 25-69.

3 J. Du, Y. Zhou, X. Su, J. J. Yu, S. Khan, H. Jiang, J. Kim, J. Woo, J. H. Kim, B. H. Choi, B. He, W. Chen, S. Zhang, R. A. Cerione, J. Auwerx, Q. Hao and H. Lin, Science, 2011, 334, 806-809.

4 H. Jiang, S. Khan, Y. Wang, G. Charron, B. He, C. Sebastian, J. Du, R. Kim, E. Ge, R. Mostoslavsky, H. C. Hang, Q. Hao and H. Lin, Nature, 2013, 496, 110-113.

5 J. L. Feldman, J. Baeza and J. M. Denu, J. Biol. Chem., 2013, 288, 31350-31356.

6 Y. Bin Teng, H. Jing, P. Aramsangtienchai, B. He, S. Khan, J. Hu, H. Lin and Q. Hao, Sci. Rep., 2014, 5, 8529.

7 M. Tan, C. Peng, K. A. Anderson, P. Chhoy, Z. Xie, L. Dai, J. Park, Y. Chen, H. Huang, Y. Zhang, J. Ro, G. R. Wagner, M. F. Green, A. S. Madsen, J. Schmiesing, B. S. Peterson, G. Xu, O. R. Ilkayeva, M. J. Muehlbauer, T. Braulke, C. Mühlhausen, D. S. Backos, C. A. Olsen, P. J. McGuire, S. D. Pletcher, D. B. Lombard, M. D. Hirschey and Y. Zhao, Cell Metab., 2014, 19, 605-617.

8 R. A. A. Mathias, T. M. M. Greco, A. Oberstein, H. G. G. Budayeva, R. Chakrabarti, E. A. A. Rowland, Y. Kang, T. Shenk and I. M. M. Cristea, Cell, 2014, 159, 1615-1625.

9 A. S. Madsen and C. A. Olsen, Angew. Chem., Int. Ed., 2012, 51, 9083-9087.

10 P. Aramsangtienchai, N. A. Spiegelman, B. He, S. P. Miller, L. Dai, Y. Zhao and H. Lin, ACS Chem. Biol., 2016, 11, 2685-2692.

11 W. Wei, X. Liu, J. Chen, S. Gao, L. Lu, H. Zhang, G. Ding, Z. Wang, Z. Chen, T. Shi, J. Li, J. Yu and J. Wong, Cell Res., 2017, 27, 898-915.

12 Z. Kutil, Z. Novakova, M. Meleshin, J. Mikesova, M. Schutkowski and C. Barinka, ACS Chem. Biol., 2018, 13, 685-693.

13 C. Moreno-Yruela, I. Galleano, A. S. Madsen and C. A. Olsen, Cell Chem. Biol., 2018, 25, 849-856.
14 J. Cao, L. Sun, P. Aramsangtienchai, N. A. Spiegelman, X. Zhang, W. Huang, E. Seto and H. Lin, Proc. Natl. Acad. Sci. U. S. A., 2019, 116, 5487-5492.

15 C. A. Olsen, ChemMedChem, 2014, 9, 434-437.

16 B. J. North, B. L. Marshall, M. T. Borra, J. M. Denu and E. Verdin, Mol. Cell, 2003, 11, 437-444.

17 T. Nagai, M. Ikeda, S. Chiba, S. I. Kanno and K. Mizuno, J. Cell Sci., 2013, 126, 4369-4380.

18 S. C. Dryden, F. A. Nahhas, J. E. Nowak, A.-S. Goustin and M. A. Tainsky, Mol. Cell. Biol., 2003, 23, 3173-3185.

19 W. Li, B. Zhang, J. Tang, Q. Cao, Y. Wu, C. Wu, J. Guo, E.A. Ling and F. Liang, J. Neurosci., 2007, 27, 2606-2616.

20 A. S. Madsen, C. Andersen, M. Daoud, K. A. Anderson, J. S. Laursen, S. Chakladar, F. K. Huynh, A. R. Colaço, D. S. Backos, P. Fristrup, M. D. Hirschey and C. A. Olsen, J. Biol. Chem., 2016, 291, 7128-7141.

21 I. Galleano, M. Schiedel, M. Jung, A. S. Madsen and C. A. Olsen, J. Med. Chem., 2016, 59, 1021-1031.

22 H. Huang, D. Zhang, Y. Wang, M. Perez-Neut, Z. Han, Y. G. Zheng, Q. Hao and Y. Zhao, Nat. Commun., 2018, 9, 3374 .

23 A. Chalkiadaki and L. Guarente, Nat. Rev. Cancer, 2015, 15, 608-624.

24 H. Jing, J. Hu, B. He, Y. L. Negrón Abril, J. Stupinski, K. Weiser, M. Carbonaro, Y. L. Chiang, T. Southard, P. Giannakakou, R. S. Weiss and H. Lin, Cancer Cell, 2016, 29, 297-310.

25 G. Donmez and T. F. Outeiro, EMBO Mol. Med., 2013, 5, 344-352.

26 G. Donmez, Curr. Drug Targets, 2013, 14, 644-647.

27 B. C. Smith and J. M. Denu, Biochemistry, 2006, 45, 272-282.

28 R. M. de Oliveira, J. Sarkander, A. G. Kazantsev and T. F. Outeiro, Front. Pharmacol., 2012, 3, 82.

29 P. Gomes, T. Fleming Outeiro and C. Cavadas, Trends Pharmacol. Sci., 2015, 36, 756-768.

30 T. F. Outeiro, E. Kontopoulos, S. M. Altmann, I. Kufareva, K. E. Strathearn, A. M. Amore, C. B. Volk, M. M. Maxwell, J.C. Rochet, P. J. McLean, A. B. Young, R. Abagyan, M. B. Feany, B. T. Hyman and A. G. Kazantsev, Science, 2007, 317, 516-519.

31 G. Eren, A. Bruno, S. Guntekin-Ergun, R. Cetin-Atalay, F. Ozgencil, Y. Ozkan, M. Gozelle, S. G. Kaya and G. Costantino, J. Mol. Graphics Modell., 2019, 89, 60-73.

32 N. A. Spiegelman, J. Y. Hong, J. Hu, H. Jing, M. Wang, I. R. Price, J. Cao, M. Yang, X. Zhang and H. Lin, ChemMedChem, 2019, 14, 744-748.

33 T. F. S. Ali, H. I. Ciftci, M. O. Radwan, R. Koga, T. Ohsugi, Y. Okiyama, T. Honma, A. Nakata, A. Ito, M. Yoshida, M. Fujita and M. Otsuka, Bioorg. Med. Chem., 2019, 27, 1767-1775.

34 K. Yamagata, Y. Goto, H. Nishimasu, J. Morimoto, R. Ishitani, N. Dohmae, N. Takeda, R. Nagai, I. Komuro, H. Suga and O. Nureki, Structure, 2014, 22, 345-352.

35 T. Rumpf, M. Schiedel, B. Karaman, C. Roessler, B. J. North, A. Lehotzky, J. Ovadi, K. I. Ladwein, K. Schmidtkunz, M. Gajer, M. Pannek, C. Steegborn, 
D. A. Sinclair, S. Gerhardt, J. Ovadí, M. Schutkowski, W. Sippl, O. Einsle and M. Jung, Nat. Commun., 2015, 6, 6263.

36 M. Schiedel, T. Rumpf, B. Karaman, A. Lehotzky, J. Oláh, S. Gerhardt, J. Ovádi, W. Sippl, O. Einsle and M. Jung, J. Med. Chem., 2016, 59, 1599-1612.

37 P. Mellini, Y. Itoh, H. Tsumoto, Y. Li, M. Suzuki, N. Tokuda, T. Kakizawa, Y. Miura, J. Takeuchi, M. Lahtela-Kakkonen and T. Suzuki, Chem. Sci., 2017, 8, 6400-6408.

38 N. Kudo, A. Ito, M. Arata, A. Nakata and M. Yoshida, Philos. Trans. R. Soc., A, 2018, B373, 20170070.

39 L.-L. Yang, H.-L. Wang, L. Zhong, C. Yuan, S.-Y. S. Liu, Z.-J. Yu, S.-Y. S. Liu, Y.-H. Yan, C. Wu, Y. Wang, Z. Wang, Y. Yu, Q. Chen and G.-B. Li, Eur. J. Med. Chem., 2018, 155, 806-823.

40 J. Y. Hong, I. R. Price, J. J. Bai and H. Lin, ACS Chem. Biol., 2019, 14, 1802-1810.

41 S. Lain, J. J. Hollick, J. Campbell, O. D. Staples, M. Higgins, M. Aoubala, A. McCarthy, V. Appleyard, K. E. Murray, L. Baker, A. Thompson, J. Mathers, S. J. Holland, M. J. R. Stark, G. Pass, J. Woods, D. P. Lane and N. J. Westwood, Cancer Cell, 2008, 13, 454-463.

42 J. Morimoto, Y. Hayashi and H. Suga, Angew. Chem., Int. Ed., 2012, 51, 3423-3427.

43 T. Suzuki, M. N. A. Khan, H. Sawada, E. Imai, Y. Itoh, K. Yamatsuta, N. Tokuda, J. Takeuchi, T. Seko, H. Nakagawa and N. Miyata, J. Med. Chem., 2012, 55, 5760-5773.

44 S. Schuster, C. Roessler, M. Meleshin, P. Zimmermann, Z. Simic, C. Kambach, C. Schiene-Fischer, C. Steegborn, M. O. Hottiger and M. Schutkowski, Sci. Rep., 2016, 6, 22643.

45 Y. Huang, J. Liu, L. Yan and W. Zheng, Bioorg. Med. Chem. Lett., 2016, 26, 1612-1617.

46 S. Moniot, M. Forgione, A. Lucidi, G. S. Hailu, A. Nebbioso, V. Carafa, F. Baratta, L. Altucci, N. Giacché, D. Passeri, R. Pellicciari, A. Mai, C. Steegborn and D. Rotili, J. Med. Chem., 2017, 60, 2344-2360.

47 S. Sundriyal, S. Moniot, Z. Mahmud, S. Yao, P. Di Fruscia, C. R. Reynolds, D. T. Dexter, M. J. E. Sternberg, E. W.-F. Lam, C. Steegborn and M. J. Fuchter, J. Med. Chem., 2017, 60, 1928-1945.

48 P. Mellini, Y. Itoh, E. E. Elboray, H. Tsumoto, Y. Li, M. Suzuki, Y. Takahashi, T. Tojo, T. Kurohara, Y. Miyake, Y. Miura, Y. Kitao, M. Kotoku, T. Iida and T. Suzuki, J. Med. Chem., 2019, 62, 5844-5862.

49 T. Rumpf, S. Gerhardt, O. Einsle and M. Jung, Acta Crystallogr., 2015, F71, 1498-1510.

50 J. Jin, B. He, X. Zhang, H. Lin and Y. Wang, J. Am. Chem. Soc., 2016, 138, 12304-12307.

51 P. Knyphausen, S. De Boor, N. Kuhlmann, L. Scislowski, A. Extra, L. Baldus, M. Schacherl, U. Baumann, I. Neundorf and M. Lammers, J. Biol. Chem., 2016, 291, 14677-14694.

52 Y. Wang, Y. M. E. Fung, W. Zhang, B. He, M. W. H. Chung, J. Jin, J. Hu, H. Lin and Q. Hao, Cell Chem. Biol., 2017, 24, 339-345.
53 L. L. Yang, W. Xu, J. Yan, H. L. Su, C. Yuan, C. Li, X. Zhang, Z. J. Yu, Y. H. Yan, Y. Yu, Q. Chen, Z. Wang, L. Li, S. Qian and G. B. Li, Med. Chem. Commun., 2019, 10, 164-168.

54 M. S. Finnin, J. R. Donigian and N. P. Pavletich, Nat. Struct. Biol., 2001, 8, 621-625.

55 S. Moniot, M. Schutkowski and C. Steegborn, J. Struct. Biol., 2013, 182, 136-143.

56 J. L. Feldman, K. E. Dittenhafer-Reed, N. Kudo, J. N. Thelen, A. Ito, M. Yoshida and J. M. Denu, Biochemistry, 2015, 54, 3037-3050.

57 I. Galleano, J. Nielsen, A. S. Madsen and C. A. Olsen, Synlett, 2017, 2169-2173.

58 N. Rajabi, M. Auth, K. R. Troelsen, M. Pannek, D. P. Bhatt, M. Fontenas, M. D. Hirschey, C. Steegborn, A. S. Madsen and C. A. Olsen, Angew. Chem., Int. Ed., 2017, 56, 14836-14841.

59 C. Moreno-Yruela, A. S. Madsen and C. A. Olsen, Protoc. Exch., 2019, DOI: 10.21203/RS.2.13042/V1.

60 B. Kitir, A. R. Maolanon, R. G. Ohm, A. R. Colaço, P. Fristrup, A. S. Madsen and C. A. Olsen, Biochemistry, 2017, 56, 5134-5146.

61 D. M. Molina, R. Jafari, M. Ignatushchenko, T. Seki, E. A. Larsson, C. Dan, L. Sreekumar, Y. Cao, P. Nordlund, D. Martinez Molina, R. Jafari, M. Ignatushchenko, T. Seki, E. A. Larsson, C. Dan, L. Sreekumar, Y. Cao and P. Nordlund, Science, 2013, 341, 84-87.

62 R. Jafari, H. Almqvist, H. Axelsson, M. Ignatushchenko, T. Lundbäck, P. Nordlund and D. M. Molina, Nat. Protoc., 2014, 9, 2100-2122.

63 W. Kabsch, Acta Crystallogr., 2010, D66, 125-132.

64 A. Vagin and A. Teplyakov, J. Appl. Crystallogr., 1997, 30, 1022-1025.

65 M. D. Winn, C. C. Ballard, K. D. Cowtan, E. J. Dodson, P. Emsley, P. R. Evans, R. M. Keegan, E. B. Krissinel, A. G. W. Leslie, A. McCoy, S. J. McNicholas, G. N. Murshudov, N. S. Pannu, E. A. Potterton, H. R. Powell, R. J. Read, A. Vagin and K. S. Wilson, Acta Crystallogr., 2011, D67, 235-242.

66 G. N. Murshudov, P. Skubák, A. A. Lebedev, N. S. Pannu, R. A. Steiner, R. A. Nicholls, M. D. Winn, F. Long and A. A. Vagin, Acta Crystallogr., 2011, D67, 355-367.

67 P. Emsley, B. Lohkamp, W. G. Scott and K. Cowtan, Acta Crystallogr., 2010, D66, 486-501.

68 F. Long, R. A. Nicholls, P. Emsley, S. Gražulis, A. Merkys, A. Vaitkus and G. N. Murshudov, Acta Crystallogr., 2017, D73, 112-122.

69 V. B. Chen, W. B. Arendall, J. J. Headd, D. A. Keedy, R. M. Immormino, G. J. Kapral, L. W. Murray, J. S. Richardson and D. C. Richardson, Acta Crystallogr., 2010, D66, 12-21.

70 B. C. Smith and J. M. Denu, Biochemistry, 2007, 46, 14478-14486.

71 B. C. Smith and J. M. Denu, J. Biol. Chem., 2007, 282, 37256-37265.

72 B. C. R. Dancy, S. A. Ming, R. Papazyan, C. A. Jelinek, A. Majumdar, Y. Sun, B. M. Dancy, W. J. Drury, R. J. Cotter, 
S. D. Taverna and P. A. Cole, J. Am. Chem. Soc., 2012, 134, 5138-5148.

73 B. M. Hirsch, Z. Du, X. Li, J. A. Sylvester, C. Wesdemiotis, Z. Wang and W. Zheng, Med. Chem. Commun., 2011, 2, 291-299.

74 H. Rink, Tetrahedron Lett., 1987, 28, 3787-3790.

75 A. S. Farooqi, J. Y. Hong, J. Cao, X. Lu, I. R. Price, Q. Zhao, T. Kosciuk, M. Yang, J. J. Bai and H. Lin, J. Med. Chem., 2019, 62, 4131-4141.

76 N. Rajabi, A. L. Nielsen and C. A. Olsen, ACS Med. Chem. Lett., 2020, 11, 1886-1892.

77 M. Kawaguchi, N. Ieda and H. Nakagawa, J. Med. Chem., 2019, 62, 5434-5452.

78 N. A. Spiegelman, I. R. Price, H. Jing, M. Wang, M. Yang, J. Cao, J. Y. Hong, X. Zhang, P. Aramsangtienchai, S. Sadhukhan and H. Lin, ChemMedChem, 2018, 13, 1890-1894.

79 Y. L. Chiang and H. Lin, Org. Biomol. Chem., 2016, 14, 2186-2190.

80 R. L. Stein, Kinetics of Enzyme Action, 2011, pp. 287-302.

81 R. A. Copeland, Evaluation of Enzyme Inhibitors in, Drug Discovery, 2013, 203-244.

82 B. P. Hubbard, A. P. Gomes, H. Dai, J. Li, A. W. Case, T. Considine, T. V. Riera, J. E. Lee, S. Y. E, D. W. Lamming, B. L. Pentelute, E. R. Schuman, L. A. Stevens, A. J. Y. Ling, S. M. Armour, S. Michan, H. Zhao, Y. Jiang, S. M. Sweitzer, C. A. Blum, J. S. Disch, P. Y. Ng, K. T. Howitz, A. P. Rolo, Y. Hamuro, J. Moss, R. B. Perni, J. L. Ellis, G. P. Vlasuk and D. A. Sinclair, Science, 2013, 339, 1216-1219.

83 K. T. Tran, J. S. Pallesen, S. M. Solbak, D. Narayanan, A. Baig, J. Zang, A. Aguayo-Orozco, R. M. C. Carmona, A. D. Garcia and A. Bach, J. Med. Chem., 2019, 62, 8028-8052.

84 Y. Zhou, H. Zhang, B. He, J. Du, H. Lin, R. A. Cerione and Q. Hao, J. Biol. Chem., 2012, 287, 28307-28314.

85 R. Deziel, J. Rahil, A. Wahhab, M. Allan and N. Nguyen, Sirtuin inhibitors, WO2009026701A1, 2009.

$86 \mathrm{~W}$. Zheng and Y. Jiang, Selenourea warhead and building method thereof, CN106632595A, 2017.

$87 \mathrm{H}$. Lin and R. Cerione, Methods for treatment of cancer by targeting SIRT5, US Pat., US20190298747, 2019.

88 H. Suga and J. Morimoto, Peptide library production method, peptide library, and screening method, US Pat., US10195578B2, 2019.
$89 \mathrm{H}$. Lin, Thiourea compounds and their us e as inhibitors of Sirt2 or Sirt5, US Pat., US10556878B2, 2020.

90 H. Dai, D. A. Sinclair, J. L. Ellis and C. Steegborn, Pharmacol. Ther., 2018, 188, 140-154.

91 S. Li, B. Wu and W. Zheng, Bioorg. Med. Chem. Lett., 2019, 29, 461-465.

92 A. G. Dodge, J. E. Richman, G. Johnson and L. P. Wackett, Appl. Environ. Microbiol., 2006, 72, 7468-7476.

93 L. L. Poulsen, R. M. Hyslop and D. M. Ziegler, Arch. Biochem. Biophys., 1979, 198, 78-88.

94 E. Zaorska, T. Hutsch, M. Gawryś-Kopczyńska, R. Ostaszewski, M. Ufnal and D. Koszelewski, Bioorg. Chem., 2019, 88, 102941.

95 M. Yoshida, M. Kijima, M. Akita and T. Beppu, J. Biol. Chem., 1990, 265, 17174-17179.

96 R. H. Skoge and M. Ziegler, J. Cell Sci., 2016, 129, 2972-2982.

97 I. Hamaidi, L. Zhang, N. Kim, M. H. Wang, C. Iclozan, B. Fang, M. Liu, J. M. Koomen, A. E. Berglund, S. J. Yoder, J. Yao, R. W. Engelman, B. C. Creelan, J. R. Conejo-Garcia, S. J. Antonia, J. J. Mulé and S. Kim, Cell Metab., 2020, 32, 420.e12-436.e12.

98 F. Hu, X. Sun, G. Li, Q. Wu, Y. Chen, X. Yang, X. Luo, J. Hu and G. Wang, Cell Death Dis., 2019, 10, 9.

99 Y. Li, M. Zhang, R. G. Dorfman, Y. Pan, D. Tang, L. Xu, Z. Zhao, Q. Zhou, L. Zhou, Y. Wang, Y. Yin, S. Shen, B. Kong, H. Friess, S. Zhao, L. Wang and X. Zou, Neoplasia, 2018, 20, 745-756.

100 J. Chen, A. W. H. Chan, K. F. To, W. Chen, Z. Zhang, J. Ren, C. Song, Y. S. Cheung, P. B. S. Lai, S. H. Cheng, M. H. L. Ng, A. Huang and B. C. B. Ko, Hepatology, 2013, 57, 2287-2298.

101 N. A. Spiegelman, X. Zhang, H. Jing, J. Cao, I. B. Kotliar, P. Aramsangtienchai, M. Wang, Z. Tong, K. M. Rosch and H. Lin, ACS Chem. Biol., 2019, 14, 2014-2023.

102 J. M. Tharp, J. T. Hampton, C. A. Reed, A. Ehnbom, P.-H. C. Chen, J. S. Morse, Y. Kurra, L. M. Pérez, S. Xu and W. R. Liu, Nat. Commun., 2020, 11, 1392.

103 R. A. Copeland, Nat. Rev. Drug Discovery, 2016, 15, 87-95. 104 Y. Jiang, J. Liu, D. Chen, L. Yan and W. Zheng, Trends Pharmacol. Sci., 2017, 38, 459-472.

105 A. S. Madsen and C. A. Olsen, J. Med. Chem., 2012, 55, 5582-5590. 